Article

\title{
Highly Productive Synthesis, Characterization, and Fluorescence and Heavy Metal Ion Adsorption Properties of Poly(2,5-dimercapto-1,3,4- thiadiazole) Nanosheets
}

\author{
Chao Li ${ }^{1,2}$, Shaojun Huang ${ }^{1, *}$, Chungang Min ${ }^{1}$, Ping Du ${ }^{1}$, Yi Xia ${ }^{1}$, Chaofen Yang ${ }^{1}$ \\ and Qiuling Huang ${ }^{1}$ \\ 1 Research Center for Analysis and Measurement, Kunming University of Science and Technology, \\ Kunming 650093, China; lichao2527@yeah.net (C.L.); minchungang@163.com (C.M.); \\ dupin515@163.com (P.D.); xiayi0125@163.com (Y.X.); yangmlh@163.com (C.Y.); hq11975@eyou.com (Q.H.) \\ 2 School of Materials Science and Engineering, Kunming University of Science and Technology, \\ Kunming 650093, China \\ * Correspondence: huangshaojun1975@163.com or sjhuang@kmust.edu.cn; Tel.: +86-0871-6511-9674
}

Received: 13 November 2017; Accepted: 22 December 2017; Published: 25 December 2017

\begin{abstract}
Poly(2,5-dimercapto-1,3,4-thiadiazole) (PBT) nanosheets were synthesized by chemical oxidative synthesis under mild conditions. The media, oxidant species, monomer concentrations, oxidant/monomer molar ratio, and temperature were optimized to achieve higher yields and better performance. The molecular structure, morphology, and properties of the nanosheets were analyzed by Fourier transform infrared (FT-IR), ultraviolet-visible (UV-Vis), and fluorescence spectroscopies, wide-angle X-ray diffraction (WAXD), matrix-assisted laser desorption/ionization/time-of-flight (MALDI-TOF) mass spectrometry, X-ray photoelectron spectroscopy (XPS), scanning electronic microscopy (SEM), transmission electron microscopy (TEM), and simultaneous thermogravimetry and differential scanning calorimetry (TG-DSC). It was found that the polymerization of 2,5-dimercapto-1,3,4-thiadiazole occurs via dehydrogenation coupling between two mercapto groups to form the-S-S- bond. PBTs show the highest polymerization yield of up to $98.47 \%$ and form uniform nanosheets with a thickness of 89 367 nm. poly(2,5-dimercapto-1,3,4-thiadiazole) polymers (PBTs) exhibit good chemical resistance, high thermostability, interesting blue-light emitting fluorescence, and wonderful heavy metal ion adsorption properties. Particularly, the PBT nanosheets having a unique synergic combination of three kinds of active $-\mathrm{S}-,-\mathrm{SH}$, and $=\mathrm{N}-$ groups with a moderate specific area of $15.85 \mathrm{~m}^{2} \mathrm{~g}^{-1}$ exhibit an ultra-rapid initial adsorption rate of $10,653 \mathrm{mg} \mathrm{g}^{-1} \mathrm{~h}^{-1}$ and an ultrahigh adsorption capacity of up to $680.01 \mathrm{mg} \mathrm{g}^{-1}$ for mercury ion, becoming ultrafast chelate nanosorbents with a high adsorption capacity. With these impressive properties, PBT nanosheets are very promising materials in the fields of water treatment, sensors, and electrodes.
\end{abstract}

Keywords: poly(2,5-dimercapto-1,3,4-thiadiazole); synthesis; characterization; nanosheets; fluorescence; adsorption; heavy metal ion; mercury; properties

\section{Introduction}

Over the past two decades, heterocyclic aromatic polymers have attracted a great deal of attention from both academic and industrial communities. Traditional heterocyclic aromatic polymers, such as polypyrrole and polythiophene, have been synthesized generally by either the electrochemical or chemical oxidative polymerization method [1-3]. In general, the electrochemical polymerization method allows for the fabrication of a uniform film with controllable thickness on the surface of electrodes. However, the low production caused by the small electrode area, the requirement of 
conducting substrates, the impurity of the resulting polymer, and pollution from the waste electrolyte restrict its wide applications [4]. By contrast, the chemical oxidative polymerization method shows some advantages involving mass production, controllable micro-morphology of polymer, easily adjustable reaction conditions, and simple doping-dedoping chemistry [5-7].

2,5-dimercapto-1,3,4-thiadiazole (bismuthiol, BT) is a heterocyclic aromatic mercaptan, which combines the features of pyrrole and thiophene according to its chemical structure. It has been reported that BT and its derivatives demonstrate excellent antibacterial properties [8-12] and strong coordination abilities to heavy metal ions [13-15] because of the sulfur (S)- and nitrogen (N)-rich subgroups and their extremely high total molar content (56\%) in BT molecules. Hence, BT can be used to easily coordinate a variety of heavy metal ions, such as $\mathrm{Co}(\mathrm{II}), \mathrm{Ni}(\mathrm{II}), \mathrm{Cu}(\mathrm{II}), \mathrm{Zn}(\mathrm{II})$, and $\mathrm{Au}(\mathrm{III})$, to form BT-M ${ }^{\mathrm{n}+}(2: 1)$ metal coordination polymer [16,17], depending on the strong coordination ability of electron-rich nitrogen and sulfur subgroups.

Taking into account the chemical and electronic structures of 2,5-dimercapto-1,3,4-thiadiazole, one may find that the 2,5-dimercapto substituents in the monomer molecules are active points and the corresponding polymer can be produced by the electrochemical or chemical oxidative polymerization method. The content of functional imino and mercapto groups in the polymer molecules should greatly increase compared with that in the monomer molecules, thus it is reasonable to infer that the heavy metals ion adsorption and antibacterial abilities of 2,5-dimercapto-1,3,4-thiadiazole polymer will also be greatly enhanced. Accordingly, it is desirable to synthesize poly(2,5-dimercapto-1,3,4-thiadiazole) (PBT) as a promising adsorbent for heavy metal ions. However, the chemical oxidative polymerization of the 1,3,4-thiadiazole ring containing derivatives has been demonstrated to be very difficult, though the electrochemical polymerization method has proved to be feasible [18,19]. Sun, Qin, and coworkers [20-22] have attempted to synthesize a 1,3,4-thiadiazole ring containing polymers by using the chemical oxidative method, but merely obtained metal coordination polymers instead of genuine polymers like polypyrrole and polythiophene. The main difficulty in synthesizing a 1,3,4-thiadiazole ring containing polymers via chemical oxidative polymerization is as follows. The five-membered heterocyclic monomers generally contain 1-3 sulfur atoms and 2-3 nitrogen atoms and the synthetic condition, especially the selection of oxidant, is quite strict. Neither too strong nor too weak oxidants are favorable for their polymerizations, otherwise leading to a ring-opening reaction, peroxidation, or failure of initiation of the polymerization [23]. Moreover, the use of transition metal salts as oxidants readily leads to the generation of complexes or coordination polymers as mentioned above. To the best of our knowledge, the intensive research on the chemical oxidative synthesis of PBT and its performance has not been reported until now.

On the other hand, the discharge of sewage containing heavy metal ions, especially mercury ions and lead ions, can do irreversible harm to the environment and human beings [24-26]. If they are absorbed and enter into the human body, they will accumulate in the human body. For instance, mercury ions can cause nervous systemic poisoning, whereas lead ions can cause damage to vital organs, both leading to serious lesions and even inducing cancer [27]. Therefore, both the detection of heavy metal ions in the environment and the treatment of heavy metal ions pollution are essential. Generally, the adsorption method is considered as a traditional and popular treatment method for heavy metal ions pollution. The adsorption of heavy metals is mainly achieved by the porous structures of the adsorbent itself or the chemical groups [28,29]. PBTs are promising adsorbents for $\mathrm{Hg}$ and $\mathrm{Pb}$ because of the multi-functional groups on their molecular chains.

In this work, PBT polymers were productively synthesized by using a chemical oxidative polymerization of BT monomers. The effects of synthetic parameters including reaction medium, oxidant species, monomer concentration, oxidant dosage, and reaction temperature on the yields of PBTs were investigated and optimized. The chemical structures, micro-morphologies, and properties were studied by ultraviolet-visible (UV-Vis) spectroscopy, Fourier transform infrared (FT-IR) spectroscopy, matrix-assisted laser desorption/ionization/time-of-flight (MALDI/TOF) mass spectroscopy, X-ray photoelectron spectroscopy (XPS), wide-angle X-ray diffraction (WAXD), scanning electronic microscopy (SEM), transmission electron microscopy (TEM), fluorescence spectroscopy 
(FLS), and thermogravimetric analysis (TGA), respectively. Finally, the adsorption performance for heavy metal ions of the polymer was studied in detail.

\section{Experimental Section}

\subsection{Chemicals}

Ammonium persulfate $\left[\left(\mathrm{NH}_{4}\right)_{2} \mathrm{~S}_{2} \mathrm{O}_{8}\right], 2,5$-dimercapto-1,3,4-thiadiazole (bismuthiol, $\left.\mathrm{BT}\right)$, iodine $\left(\mathrm{I}_{2}\right)$, sodium hypochlorite $(\mathrm{NaClO})$, hydrogen peroxide $\left(\mathrm{H}_{2} \mathrm{O}_{2}\right)$, ferric chloride $\left(\mathrm{FeCl}_{3}\right)$, perchloric acid $\left(\mathrm{HClO}_{4}\right), \mathrm{N}, \mathrm{N}$-dimethylformamide (DMF), $\mathrm{N}$-methy1-2-pyrrolidone (NMP), tetrahydrofuran (THF), dimethyl sulfoxide (DMSO), acetone $\left(\mathrm{CH}_{3} \mathrm{COCH}_{3}\right)$, nitromethane $\left(\mathrm{CH}_{3} \mathrm{NO}_{2}\right)$, methanol $\left(\mathrm{CH}_{3} \mathrm{OH}\right)$, ethanol $\left(\mathrm{C}_{2} \mathrm{H}_{5} \mathrm{OH}\right)$, hydrochloric acid $(\mathrm{HCl})$, ammonia $\left(\mathrm{NH}_{3} \cdot \mathrm{H}_{2} \mathrm{O}\right), \mathrm{Hg}\left(\mathrm{NO}_{3}\right)_{2}, \mathrm{~Pb}\left(\mathrm{NO}_{3}\right)_{2}, \mathrm{AgNO}_{3}$, $\mathrm{Co}\left(\mathrm{NO}_{3}\right)_{2}, \mathrm{Cr}\left(\mathrm{NO}_{3}\right)_{3}, \mathrm{Cd}\left(\mathrm{NO}_{3}\right)_{2}, \mathrm{Fe}\left(\mathrm{NO}_{3}\right)_{3}, \mathrm{Zn}\left(\mathrm{NO}_{3}\right)_{2}, \mathrm{Cu}\left(\mathrm{NO}_{3}\right)_{2}, \mathrm{Mg}\left(\mathrm{NO}_{3}\right)_{2}, \mathrm{NaNO}_{3}, \mathrm{KNO}_{3}$, $\mathrm{Al}\left(\mathrm{NO}_{3}\right)_{3}$, dithranol (DIT), silver trifluoroacetate $\left(\mathrm{CF}_{3} \mathrm{COOAg}\right)$, and other chemicals were purchased from Chemical Reagent Corp. in Kunming, China. All reagents and solvents were of analytical reagent grade and used as received.

\subsection{Synthesis of PBT Nanosheets}

A typical synthesis of PBT was conducted as follows: $0.3005 \mathrm{~g}(2.0 \mathrm{mmol})$ of BT monomer was dissolved in $10 \mathrm{~mL}$ of absolute ethanol with the aid of stirring. The solution was transferred to a $100-\mathrm{mL}$ glass-stoppered conical flask and stirred at $25^{\circ} \mathrm{C}$, followed by the dropwise addition of $30 \mathrm{~mL}$ of ethanol solution containing $0.7614 \mathrm{~g}(3.0 \mathrm{mmol})$ of $\mathrm{I}_{2}$. The solution exhibited a change in color from pale yellow to brown black once the oxidant solution was added, and a polymer precipitation appeared within 2-3 min. The reaction was carried out for an additional $24 \mathrm{~h}$ to ensure that all of the monomers were polymerized. At the end of the reaction, $200 \mathrm{~mL}$ of deionized water was added to the reaction mixture to adequately precipitate the polymer, and then the polymer precipitates were separated by centrifugation. The polymer precipitates were thereafter washed with excess deionized water and ethanol until the washing solution was colorless or light colored, and finally dried at $80^{\circ} \mathrm{C}$ in air for $24 \mathrm{~h}$, producing PBT nanosheet powders.

\subsection{Fluorescent Property Investigation}

First, $0.0010 \mathrm{~g}$ of PBT was dissolved in NMP to confect a $10 \mathrm{mg} \mathrm{L}^{-1}$ solution. This solution was stepwise diluted to 200, 150, 100, 50, and $10 \mu \mathrm{g} \mathrm{L}^{-1}$ with NMP. The excitation and emission spectra of these solutions were examined to find out which concentration could emit the strongest fluorescence. The optimum concentration was chosen for the subsequent experiments. On the other hand, the polymer organic solution was reacted with an aqueous solution of metal ion, and the resulting mixed solution was used to detect the fluorescence intensity change to exploit the potential of the polymer for the detection of certain metal ions. The typical fluorometric measurements of polymer-metal complex solutions were carried out as follows. Polymer-metal complex solutions used for fluorescence measurements were prepared by mixing $50 \mu \mathrm{L}$ of polymer solution $\left(10,000 \mu \mathrm{g} \mathrm{L}^{-1}\right)$ in NMP with $1.0 \mathrm{~mL}$ of aqueous metal salt solutions $\left(1.0 \times 10^{-4} \mathrm{~mol} \mathrm{~L}^{-1}\right)$ at room temperature, and then increasing the solution to a constant volume with the addition of $10.0 \mathrm{~mL}$ by NMP. The terminal concentrations of the polymer and metal ion were $50 \mu \mathrm{g} \mathrm{L}^{-1}$ and $1.0 \times 10^{-5} \mathrm{~mol} \mathrm{~L}^{-1}$, respectively. The metal ions investigated were $\mathrm{Na}^{+}, \mathrm{Mg}^{2+}, \mathrm{Al}^{3+}, \mathrm{K}^{+}, \mathrm{Cr}^{3+}, \mathrm{Fe}^{3+}, \mathrm{Co}^{2+}, \mathrm{Cu}^{2+}, \mathrm{Zn}^{2+}, \mathrm{Ag}^{+}, \mathrm{Cd}^{2+}$, and $\mathrm{Pb}^{2+}$ as their nitrate salts. It was found that no precipitate was observed even though $20 \%$ (volume fraction) water was added into the polymer solution in NMP. All of the fluorescence measurements were operated right after the test solutions were prepared and thoroughly mixed. The fluorescence emission spectra were recorded based on these mixed solutions with a constant polymer concentration of $50 \mu \mathrm{g} \mathrm{L}^{-1}$. The slit widths for the excitation and emission were both fixed at $5.0 \mathrm{~nm}$. 


\subsection{Adsorption Experiments}

\subsubsection{Single Metal Ion Adsorption onto the Nanosheets}

Different stock solutions containing one of the following metal ions, $\mathrm{Pb}^{2+}, \mathrm{Hg}^{2+}, \mathrm{Ag}^{+}, \mathrm{Co}^{2+}, \mathrm{Cr}^{3+}$, $\mathrm{Cd}^{2+}, \mathrm{Fe}^{3+}, \mathrm{Zn}^{2+}$ or $\mathrm{Cu}^{2+}$, were confected in advance. A typical adsorption operation taking $\mathrm{Pb}^{2+}$ solution as an example is described as follows. First, $50 \mathrm{mg}$ of PBT nanosheets was added to $50 \mathrm{~mL}$ of $\mathrm{Pb}^{2+}$ solution at an initial concentration of $200 \mathrm{mg} \mathrm{L}^{-1}$, and the mixture was then vigorously stirred for $24 \mathrm{~h}$ in a water bath at $25^{\circ} \mathrm{C}$. After adsorption, the mixture was separated into a precipitate and a supernatant by centrifugation and the concentration of $\mathrm{Pb}^{2+}$ ions remaining in the supernatant was determined by inductively coupled plasma atomic emission spectrometry (ICP-AES).

The adsorption capacity $(Q)$ and adsorption ratio $(q)$ were calculated according to the following equations:

$$
\begin{gathered}
Q=\frac{\left(C_{0}-C\right) V}{m} \\
q=\frac{\left(C_{0}-C\right)}{C_{0}} \times 100 \%
\end{gathered}
$$

where $Q\left(\mathrm{mg} \mathrm{g}^{-1}\right)$ and $q(\%)$ are the adsorption capacity and adsorption ratio, respectively; $C_{0}\left(\mathrm{mg} \mathrm{L}^{-1}\right)$ and $C\left(\mathrm{mg} \mathrm{L}^{-1}\right)$ are the initial concentration of the metal ion and the metal ion concentration after adsorption, respectively; $V(\mathrm{~L})$ is the initial volume of metal ion solution; and $m(\mathrm{~g})$ is the weight of the nanosheets added.

\subsubsection{Adsorption Selectivity}

The mixed cation solution containing $\mathrm{Pb}^{2+}, \mathrm{Hg}^{2+}, \mathrm{Ag}^{+}, \mathrm{Co}^{2+}, \mathrm{Cr}^{3+}, \mathrm{Cd}^{2+}, \mathrm{Fe}^{3+}, \mathrm{Zn}^{2+}$, and $\mathrm{Cu}^{2+}$ ions were used to examine the adsorption selectivity of PBT nanosheets. All of the metal ions used were in the same concentration of $20 \mathrm{mg} \mathrm{L}^{-1}$. In the examination, $50 \mathrm{mg}$ of PBT nanosheets was added into $50 \mathrm{~mL}$ of mixed cation solution. The mixture was then vigorously stirred at $25^{\circ} \mathrm{C}$ for $24 \mathrm{~h}$. After adsorption, the mixture was separated into a precipitate and a supernatant by centrifugation for further analyses. The adsorption capacity and adsorption ratio of each metal ion in the mixed cation solution were calculated using the method described in Section 2.4.1.

\subsection{Characterization and Measurements}

The UV-Vis spectra of the polymer solutions or dispersions $\left(500 \mathrm{mg} \mathrm{L}^{-1}\right)$ in NMP were recorded on a TU-1901 UV-Vis spectrophotometer (Beijing Purkinje General Instrument Co., Ltd., Beijing, China) in a wavelength range of $190-900 \mathrm{~nm}$ at a scanning rate of $400 \mathrm{~nm} \mathrm{~min}{ }^{-1}$. Fourier transform infrared (FT-IR) spectra of the $\mathrm{PBT} / \mathrm{KBr}$ (weight ratio of 1:60) pellets were recorded on a Bruker TENSOR 27 FT-IR spectrometer (Karlsruhe, Germany) with a resolution of $4 \mathrm{~cm}^{-1}$, by the transmittance method. Wide-angle X-ray diffraction (WAXD) scanning was carried out on a Rigaku International Corporation D/max 2000 X-ray diffractometer (Tokyo, Japan) with $\mathrm{Cu} \mathrm{K} \alpha$ radiation in a Bragg angle range of $10-80^{\circ}$ at a scanning rate of $1^{\circ} \mathrm{min}^{-1}$. The matrix-assisted laser desorption/ionization/time-of-flight (MALDI/TOF) mass spectra of PBT in THF, using dithranol (DIT) as a matrix and silver trifluoroacetate $\left(\mathrm{CF}_{3} \mathrm{COOAg}\right)$ as a sensitizer, were recorded on a Bruker Daltonik GmbH autoflex speed TOF/TOF mass spectrometer (Bruker Corporation, Billerica, MA, USA). The XPS spectra were taken by a PHI5000 Versaprobe-II multifunctional scanning and imaging photoelectron spectrometer (Physical Electronics Inc., Chigasaki, Japan) equipped with an $\mathrm{Al} \mathrm{K} \alpha \mathrm{X}$-ray source. Thermogravimetric (TG) analysis was performed on a NETZSCH STA 449F3 TG-DSC simultaneous thermal analyzer (NETZSCH Group, Bavaria, Germany) in a temperature range from room temperature to $1000{ }^{\circ} \mathrm{C}$ at a heating rate of $20^{\circ} \mathrm{C} \mathrm{min}^{-1}$ under a flow of nitrogen. The fluorescence excitation and emission spectra were obtained by a F-7000 fluorescence-phosphorescence spectrophotometer (Hitachi High-Technologies Corporation, Tokyo, Japan). The size and morphology of the PBT nanosheets were 
analyzed by a FEI Tecnai G2 TF30 S-Twin field emission TEM (Eindhoven, The Netherlands) and a FEI Quanta X50 scanning electron microscope (SEM). The samples for TEM observation were prepared by dropping their suspension in alcohol onto copper mesh, while the samples for SEM observation were prepared by dropping their suspension in alcohol onto conductive tape. The atomic emission spectra of metal ions in water samples were recorded on a Prodigy High Dispersion ICP-AES (Leeman Labs Inc., Hudson, NH, USA). Nitrogen adsorption/desorption measurements at $77.4 \mathrm{~K}$ were performed after degassing the PACA powders under high vacuum at $100{ }^{\circ} \mathrm{C}$ for at least $20 \mathrm{~h}$ using a DZF-6030A vacuum drying oven (Suzhou Jiangdong Precision Instruments Co., Ltd., Suzhou, China). The specific surface area was calculated by applying the Brunauer-Emmett-Teller (BET) model to the adsorption or desorption branches of the isotherms $\left(\mathrm{N}_{2}\right.$ at $\left.77.4 \mathrm{~K}\right)$.

\section{Results and Discussion}

\subsection{Synthesis PBT Nanosheets}

\subsubsection{Selection of Polymerization Media}

The screening of an appropriate medium is very important for chemical oxidative polymerization [30,31]. The solubility tests show that $\mathrm{BT}$ can be dissolved well in $\mathrm{DMF}, \mathrm{CH}_{3} \mathrm{OH}$, $\mathrm{C}_{2} \mathrm{H}_{5} \mathrm{OH}, \mathrm{NMP}$, DMSO, $\mathrm{CH}_{3} \mathrm{COCH}_{3}$, THF, and $1 \mathrm{~mol} \mathrm{~L}^{-1} \mathrm{NH}_{3} \cdot \mathrm{H}_{2} \mathrm{O}$, but partially dissolved in $\mathrm{CH}_{3} \mathrm{NO}_{2}$ and slightly dissolved in $1 \mathrm{~mol} \mathrm{~L}^{-1} \mathrm{HCl}$, as summarized in Table S1. Among these media, DMF, $\mathrm{CH}_{3} \mathrm{OH}$, and $\mathrm{C}_{2} \mathrm{H}_{5} \mathrm{OH}$ can also dissolve commonly used oxidants such as $\left(\mathrm{NH}_{4}\right)_{2} \mathrm{~S}_{2} \mathrm{O}_{8}, \mathrm{FeCl}_{3}$, and $\mathrm{I}_{2}$, so these three media can be used for the polymerization of BT. However, weak solvents as $\mathrm{CH}_{3} \mathrm{NO}_{2}$ and $1 \mathrm{~mol} \mathrm{~L}-1 \mathrm{HCl}$, strong volatile THF and $\mathrm{CH}_{3} \mathrm{COCH}_{3}$, and alkaline $\mathrm{NH}_{3} \cdot \mathrm{H}_{2} \mathrm{O}$, together with high boiling solvents like NMP and DMSO are not suitable for the polymerization of BT monomers. Upon adding the $\mathrm{I}_{2}$ oxidant solution to the BT monomer solution, the color of the monomer solution changed immediately from transparent pale yellow to brown yellow and then to brown black, and yellow precipitates appeared at the bottom of the reactor within several minutes, indicating that the chemical oxidative polymerization of $\mathrm{BT}$ monomers really occurred. When $\mathrm{I}_{2}$ acted as the oxidant and $\mathrm{CH}_{3} \mathrm{OH}, \mathrm{C}_{2} \mathrm{H}_{5} \mathrm{OH}$, or DMF was used as the oxidant, the yields of $82.23 \%$, $80.20 \%$, and $38.5 \%$ were obtained, respectively. As can be seen in Figure 1a, the UV-Vis absorption at a long wavelength $(700-900 \mathrm{~nm})$ was relatively stronger when $\mathrm{C}_{2} \mathrm{H}_{5} \mathrm{OH}$ was used, indicating the higher average molecular weight of the polymer. On the other hand, since $\mathrm{C}_{2} \mathrm{H}_{5} \mathrm{OH}$ is also an environmentally friendly reaction medium, we choose ethanol as the best polymerization medium in the subsequent synthesis.
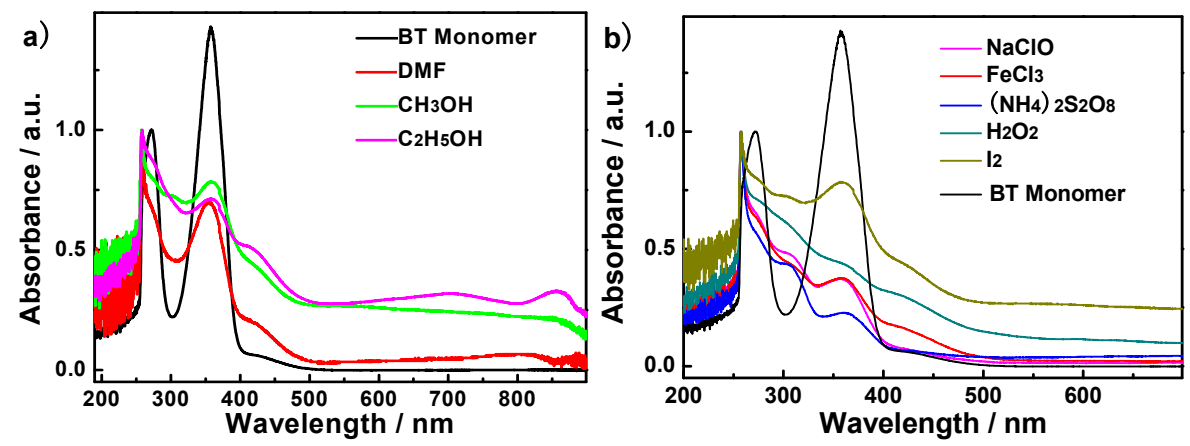

Figure 1. The UV-Vis spectra of 2,5-dimercapto-1,3,4-thiadiazole (BT) monomer and poly(2,5-dimercapto1,3,4-thiadiazole) (PBT) polymers synthesized (a) in different media with an $\mathrm{I}_{2} / \mathrm{BT}$ molar ratio of 1.5, and (b) with the oxidant/BT molar ratio of 1.5 in ethanol, together with an initial BT concentration of $50 \mathrm{mmol} \mathrm{L}^{-1}$ at $25^{\circ} \mathrm{C}$ for $24 \mathrm{~h}$. 


\subsubsection{Screening of the Oxidant Species}

The selection of the oxidant is also critical for the chemical oxidative polymerization of BT monomers (Scheme 1), which is related to the success or failure of the initiation of the polymerization. A variety of oxidants, including $\mathrm{I}_{2}, \mathrm{H}_{2} \mathrm{O}_{2},\left(\mathrm{NH}_{4}\right)_{2} \mathrm{~S}_{2} \mathrm{O}_{8}, \mathrm{FeCl}_{3}, \mathrm{NaClO}$, and $\mathrm{HClO}_{4}$, were explored to polymerize BT monomers, and the resulting yields were $82 \%, 91.80 \%, 74.71 \%, 100.32 \%, 18.08 \%$, and $0 \%$, respectively. When $\mathrm{FeCl}_{3}$ was used, the yield exceeded $100 \%$, because iron ions are easy to complex with the $\mathrm{S}$ and $\mathrm{N}$ subgroups in the polymer chains and cannot be totally removed. When $\mathrm{HClO}_{4}$ was used, no product was obtained at all. It should be noted that the polymerization of BT can produce hydrogen ions, but too many hydrogen ions may inhibit the polymerization reaction and promote its reverse reaction. In general, $\mathrm{HClO}_{4}$ has been used as a strong acid instead of an efficient oxidant in the polymerization of heterocyclic aromatic monomers. Small amounts of oligomers might be produced when perchloric acid was used as an oxidant, but these low molecular weight oligomers were difficult to be precipitated from the reaction solution and were easily washed off during the purification process. By contrast, when $\mathrm{I}_{2}$ or $\mathrm{H}_{2} \mathrm{O}_{2}$ was used as the oxidant, the yield was considerable, and the final reduced products of the oxidants were $\mathrm{I}^{-}$and $\mathrm{H}_{2} \mathrm{O}$, respectively, which greatly facilitates post-processing so as to obtain a pure product. From the UV-Vis spectra in Figure 1b, one can see that the PBTs prepared with $\mathrm{I}_{2}$ and $\mathrm{H}_{2} \mathrm{O}_{2}$ exhibited stronger absorptions at $358 \mathrm{~nm}$ and longer wavelengths when compared with those prepared with other oxidants. Thus, $\mathrm{I}_{2}$ and $\mathrm{H}_{2} \mathrm{O}_{2}$ were selected as the optimal oxidants for polymerizing BT monomers.

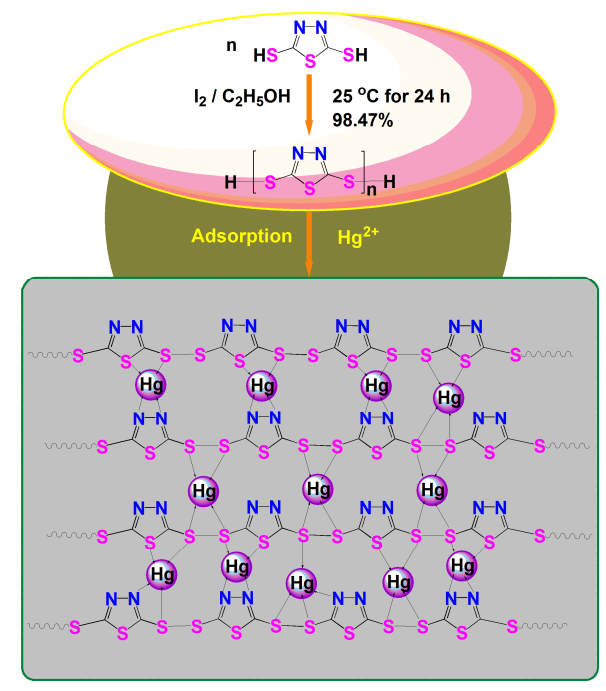

Scheme 1. Chemical oxidative polymerization of 2,5-dimercapto-1,3,4-thiadiazole (BT) and the proposed adsorption mechanism of PBT nanosheets for $\mathrm{Hg}^{2+}$.

\subsubsection{Optimization of the BT Concentrations, Oxidant/BT Molar Ratios, and Polymerization Temperature}

In the oxidation system of $\mathrm{I}_{2} / \mathrm{C}_{2} \mathrm{H}_{5} \mathrm{OH}$, when the molar ratios of oxidant to monomer were changed from 0.25 to $0.5,1,1.5$, and 2 , the polymerization yields reached $8.72 \%, 68.56 \%, 80.20 \%$, $98.47 \%$, and $96.45 \%$, respectively. It can be seen that the polymerization yield increased rapidly and then reached the maximum with increasing the $\mathrm{I}_{2} / \mathrm{BT}$ molar ratios from 0.25 to 1.5. Further increasing the $\mathrm{I}_{2} / \mathrm{BT}$ molar ratio barely changed the polymerization yield. As the $\mathrm{I}_{2} / \mathrm{BT}$ molar ratio was fixed at 1.5 and the BT concentration increased from 30.65 to 43.75 , and $50 \mathrm{mmol} \mathrm{L}^{-1}$, the yield increased dramatically from $58.72 \%$ to $65.40 \%$ and $98.47 \%$, and then decreased slightly $(92.91 \%)$ upon further increasing the BT concentration to $58.25 \mathrm{mmol} \mathrm{L}^{-1}$. Obviously, few reaction active centers are created at low monomer concentrations and low $\mathrm{I}_{2} / \mathrm{BT}$ molar ratios, whilst the growth of polymeric chains is easier to be terminated with very high monomer concentrations and very high 
$\mathrm{I}_{2} / \mathrm{BT}$ molar ratios [32,33], explaining why a good polymerization yield $(98.47 \%)$ of PBT was obtained at a moderate $\mathrm{I}_{2} / \mathrm{BT}$ molar ratio (1.5) and a moderate $\mathrm{BT}$ concentration $\left(50 \mathrm{mmol} \mathrm{L}^{-1}\right)$. With raising the polymerization temperatures from $0{ }^{\circ} \mathrm{C}$ to $5{ }^{\circ} \mathrm{C}, 25^{\circ} \mathrm{C}, 40{ }^{\circ} \mathrm{C}$, and $50{ }^{\circ} \mathrm{C}$, the yields first rose and then fell, and they were $31.17 \%, 72.17 \%, 98.47 \%, 77.85 \%$, and $56.18 \%$, respectively. The PBTs exhibited maximal polymerization yields at $25^{\circ} \mathrm{C}$. Too high a temperature, however, induces drastic chain termination, whereas too low a temperature can cause a low speed of polymerization and less monomer initiation [32,33]. This explains why a moderate temperature of $25^{\circ} \mathrm{C}$ is the optimal temperature for the synthesis of PBT.

In the oxidation system of $\mathrm{H}_{2} \mathrm{O}_{2} / \mathrm{C}_{2} \mathrm{H}_{5} \mathrm{OH}$, the $\mathrm{H}_{2} \mathrm{O}_{2} / \mathrm{BT}$ molar ratios, monomer concentration, and polymerization temperature were optimized according to the yields in the same way. It was found that the highest yield of up to $97.20 \%$ was obtained when the PBT was synthesized with an initial BT concentration of $58.25 \mathrm{mmol} \mathrm{L}^{-1}$ and an $\mathrm{H}_{2} \mathrm{O}_{2} / \mathrm{BT}$ molar ratio of 3.53 in ethanol at $25^{\circ} \mathrm{C}$ for $24 \mathrm{~h}$. In fact, the PBT polymer synthesized in the $\mathrm{I}_{2} / \mathrm{C}_{2} \mathrm{H}_{5} \mathrm{OH}$ oxidation system has a nearly equal yield compared with that synthesized in the $\mathrm{H}_{2} \mathrm{O}_{2} / \mathrm{C}_{2} \mathrm{H}_{5} \mathrm{OH}$ oxidation system.

\subsection{Chemical Structure of PBT Nanosheets}

\subsubsection{FT-IR Spectra}

Figure 2 shows the FT-IR absorptions of BT monomer and PBT polymers synthesized with $\mathrm{I}_{2}$ and $\mathrm{H}_{2} \mathrm{O}_{2}$. For BT monomer, the characteristic bands appearing at 2476, 1637, 1501, 1387, 1262, 1119, $1049,938,749,712,653$, and $533 \mathrm{~cm}^{-1}$ can be assigned to $-\mathrm{S}-\mathrm{H}$ stretch, $\mathrm{C}=\mathrm{N}$ stretch, N-H in-plane deformation, thiadiazole ring skeleton stretch, thioamide II mode, thiadiazole ring skeleton stretch, $\mathrm{N}-\mathrm{N}$ stretch, $\mathrm{C}=\mathrm{S}$ stretch, $\mathrm{N}-\mathrm{H}$ torsion, $\mathrm{C}-\mathrm{S}-\mathrm{C}$ endocyclic asymmetric stretch, $\mathrm{C}-\mathrm{S}-\mathrm{C}$ endocyclic symmetric stretch, and S-C-S stretch (Table S4) [8,34-36]. However, compared with BT monomer, it was observed that the $-\mathrm{S}-\mathrm{H}$ stretch band at $2476 \mathrm{~cm}^{-1}$ disappeared and a new band at $492 \mathrm{~cm}^{-1}$, corresponding to S-S stretch, appeared in each PBT polymer spectrum, which signifies that the polymerization of BT monomer occurs through $-\mathrm{S}-\mathrm{S}-$ bond linkages $[37,38]$. For PBT polymers, the bands at 1501, 1262, 938, 749, and $712 \mathrm{~cm}^{-1}$ weakened and shifted slightly in position or disappeared because the Fermi resonance modes of the monomer units were basically inhibited after the formation of macromolecular chains [8]. On the other hand, the bands at 1637, 1387, and $1049 \mathrm{~cm}^{-1}$ in the BT monomer spectrum were shifted slightly to lower wavenumbers and became obviously more intense after BT monomers were polymerized because that the formation of macromolecular chains changed the electron cloud density of each group. Interestingly, the PBT polymers synthesized with $\mathrm{I}_{2}$ and $\mathrm{H}_{2} \mathrm{O}_{2}$ were similar in frequency and morphology of FT-IR absorptions, indicating their similar macromolecular structures.

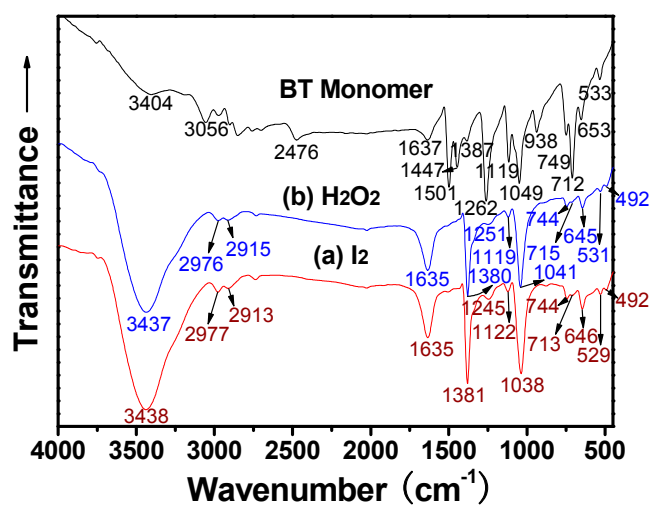

Figure 2. FT-IR spectra of BT monomer and PBT polymers prepared with (a) an $\mathrm{I}_{2} / \mathrm{BT}$ molar ratio of 1.5 and an initial BT concentration of $50 \mathrm{mmol} \mathrm{L}^{-1}$, and (b) an $\mathrm{H}_{2} \mathrm{O}_{2} / \mathrm{BT}$ molar ratio of 3.53 and an initial BT concentration of $58.25 \mathrm{mmol} \mathrm{L}^{-1}$ in ethanol at $25^{\circ} \mathrm{C}$ for $24 \mathrm{~h}$. 


\subsubsection{UV-Vis Spectra}

Figure S1 shows the UV-Vis absorption spectra of the NMP solution of BT monomer and PBT polymers. BT monomer exhibited two strong absorption peaks centered at 272 and $358 \mathrm{~nm}$, which are assigned to the $\pi \rightarrow \pi^{*}$ transition of the thiadiazole moiety and the $\mathrm{n} \rightarrow \pi^{*}$ transition of the $-\mathrm{S}-(\mathrm{HS}) \mathrm{C}=\mathrm{N}-$ moiety in a BT molecule $[39,40]$. However, the spectrum of PBT polymer synthesized with $\mathrm{H}_{2} \mathrm{O}_{2}$ presented a broad and tailed absorption peak at $270 \mathrm{~nm}$, which may be relative to the formation of polymer macromolecular structures. By contrast, the spectrum of PBT polymer synthesized with $\mathrm{I}_{2}$ showed four peaks centered at 258,358,702, and $855 \mathrm{~nm}$, respectively. These two new absorptions at 702 and $855 \mathrm{~nm}$ are both attributed to an intramolecular charge transfer of the entire macromolecules [41]. The slight blue shift of the first peak from $272 \mathrm{~nm}$ to $258 \mathrm{~nm}$ after polymerization may be also ascribed to the formation of polymer macromolecules [39]. In summary, the differences in UV absorptions of the polymers and monomer demonstrated that the polymerization of BT monomers indeed happened. Additionally, the results indicate that the PBT polymer synthesized with $\mathrm{I}_{2}$ may possess a higher average molecular weight as compared with that synthesized with $\mathrm{H}_{2} \mathrm{O}_{2}$.

\subsubsection{Wide Angle X-ray Diffraction}

The wide-angle X-ray diffraction (WAXD) spectra of PBT polymer powders and BT monomer are shown in Figure 3. Both the polymers and the monomer presented multiple sharp diffraction peaks, but both the number of diffraction peaks and peak positions were not similar (See Table S5 and Figure 3). The PBT polymers synthesized with $\mathrm{I}_{2}$ and $\mathrm{H}_{2} \mathrm{O}_{2}$ exhibited the same number of diffraction peaks, whilst the $2 \theta$ values of these diffraction peaks varied by about $0.1^{\circ}$ (See Table S5). The former displayed five main diffraction peaks at $20.6^{\circ}, 20.8^{\circ}, 26.2^{\circ}, 27.8^{\circ}$, and $31.9^{\circ}$, whereas the latter displayed five main diffraction peaks at $20.7^{\circ}, 20.9^{\circ}, 26.3^{\circ}, 27.9^{\circ}$, and $32.0^{\circ}$. These results reveal the crystalline nature of the PBT polymers and a slight difference in crystal structures [17], supporting the SEM and TEM results. It was found that the number of diffraction peaks or their $2 \theta$ values of the polymer may change if the electrochemical or chemical polymerization method is varied. Our PBT polymers differ significantly in the number of diffraction peaks and $2 \theta$ values with the crystalline PBT chemically synthesized with ammonium persulfate in mixed solvent $\mathrm{CH}_{3} \mathrm{OH} / \mathrm{H}_{2} \mathrm{O}$ and the electrochemically synthesized less crystalline PBT [42]. Compared with the PBT polymers, BT monomer showed more diffraction peaks, mainly at $13.3^{\circ}, 17.0^{\circ}, 19.8^{\circ}, 20.9^{\circ}, 22.1^{\circ}, 22.5^{\circ}, 22.9^{\circ}, 26.5^{\circ}, 26.9^{\circ}, 27.8^{\circ}, 29.4^{\circ}, 29.8^{\circ}$, and $30.9^{\circ}$. The different peaks suggest changes in the unit-cell symmetry between the polymers and monomer [42].

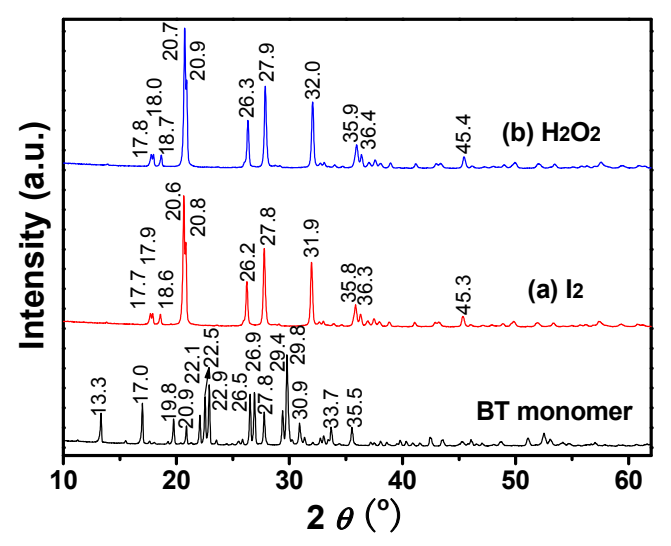

Figure 3. Wide-angle $X$-ray diffraction (WAXD) diffractograms of BT monomer and PBT polymers prepared with (a) an $\mathrm{I}_{2} / \mathrm{BT}$ molar ratio of 1.5 and an initial BT concentration of $50 \mathrm{mmol} \mathrm{L}^{-1}$, and (b) an $\mathrm{H}_{2} \mathrm{O}_{2} / \mathrm{BT}$ molar ratio of 3.53 and an initial BT concentration of $58.25 \mathrm{mmol} \mathrm{L}^{-1}$ in ethanol at $25^{\circ} \mathrm{C}$ for $24 \mathrm{~h}$. 


\subsubsection{MALDI/TOF Mass Spectra}

The molecular weights of PBT polymers were estimated by MALDI/TOF mass spectrometry (Figure $4 \mathrm{a}-\mathrm{f}$ ) and the proposed compositions regarding each quasi-molecular ion are summarized in Table S6. The molecular weight, i.e., the degree of polymerization of PBTs, depended significantly on the oxidant species applied. It was found from Figure $4 \mathrm{a}-\mathrm{c}$ that the molecular weights of the THF soluble part of PBT polymer salts prepared with $\mathrm{I}_{2}$ are mostly in the range of 859.1 2910.4, corresponding to the polymerization degree of $6 \sim 16$, whilst those prepared with $\mathrm{H}_{2} \mathrm{O}_{2}$ are mainly in the range of 863.1 3780.6, corresponding to the polymerization degree of $6 \sim 24$ (Figure $4 \mathrm{~d}-\mathrm{f}$ ). It is surprisingly noted that the actual polymerization degree cannot be simply calculated as the $m / z$ value divided by the mass of a BT monomer unit $\left(-\mathrm{C}_{2} \mathrm{~N}_{2} \mathrm{~S}_{3}-, m=148.21\right)$. The calculated mass differential $(\Delta m / z)$ between some neighboring quasi-molecular ions is about 105 112, a value approximately equivalent to the mass of $\mathrm{Ag}^{+}$(107.9). This reveals that the PBT molecules were forming metal ion adducts with $\mathrm{Ag}^{+}$. Since the $-\mathrm{S}-,-\mathrm{SH}$, and $=\mathrm{N}$ - groups on the PBT molecules have a strong affinity toward $\mathrm{Ag}+, \mathrm{H}^{+}, \mathrm{K}^{+}, \mathrm{Na}^{+}$, or other cations from the silver trifluoroacetate sensitizer, dithranol matrix, THF solvent, or glassware, the sulfur and nitrogen atoms are sometimes ionized by these ions in order to form quasi-molecule ions or metal ion adducts (See Table S6) $[32,33]$. The -SH terminal groups are sometimes eliminated from the polymer chains because of laser irradiation. Thus, the quasi-molecule ions or metal ion adducts can be attributed to a composition as expressed in the general Formula (3):

$$
\left[\mathrm{H}\left(\mathrm{C}_{2} \mathrm{~N}_{2} \mathrm{~S}_{3}\right)_{n} \mathrm{H}+\mathrm{aAg}+\mathrm{bK}+\mathrm{cNa}+\mathrm{dH}-\mathrm{eS}\right]^{+}(\mathrm{n} \geq 2 ; \mathrm{a}, \mathrm{b}, \mathrm{c}, \mathrm{d}, \mathrm{e}=0,1,2,3, \ldots)
$$

As can be seen from Table S6 of the Supplementary Materials, the THF soluble parts of PBTs synthesized with different oxidants have wide polymer chain length distributions and similar chain structures but different polymerization degrees. Furthermore, the calculated values of $m / z$ for the proposed compositions are in good agreement with the experimental values of $m / z$, suggesting the rationality of the proposed compositions as expressed in Formula (3). After all, about $85 \mathrm{wt} \%$ of PBT polymer salts are insoluble in THF, and their molecular weights can be measured neither by MALDI/TOF mass spectrometry nor by high temperature gel permeation chromatography (HT-GPC). Presumably, the insoluble parts may have far higher molecular weights than the soluble parts. On the other hand, $\mathrm{PBT}$ polymer prepared with $\mathrm{I}_{2}$ exhibited weaker solubility in common solvents including THF, NMP, DMSO, $\mathrm{C}_{2} \mathrm{H}_{5} \mathrm{OH}, \mathrm{CH}_{3} \mathrm{OH}, \mathrm{CH}_{3} \mathrm{COCH}_{3}$, and $\mathrm{CH}_{3} \mathrm{NO}_{2}$ in comparison with that prepared with $\mathrm{H}_{2} \mathrm{O}_{2}$, as can be seen from Table $\mathrm{S} 1$. This indicates that the PBT polymer prepared with $\mathrm{I}_{2}$ possesses relatively higher molecular weights.
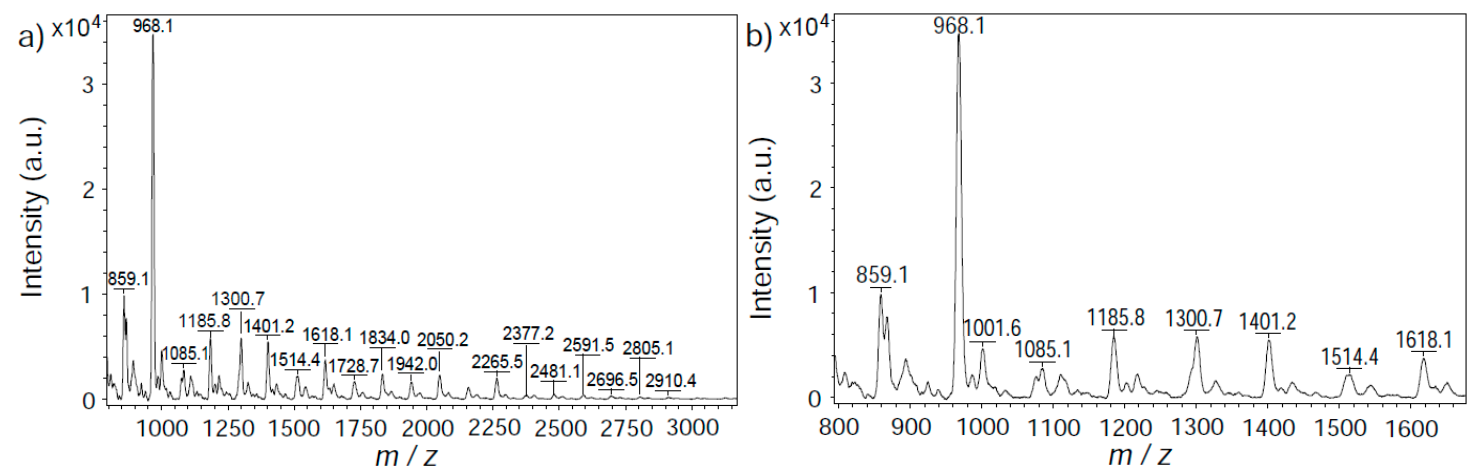

Figure 4. Cont. 

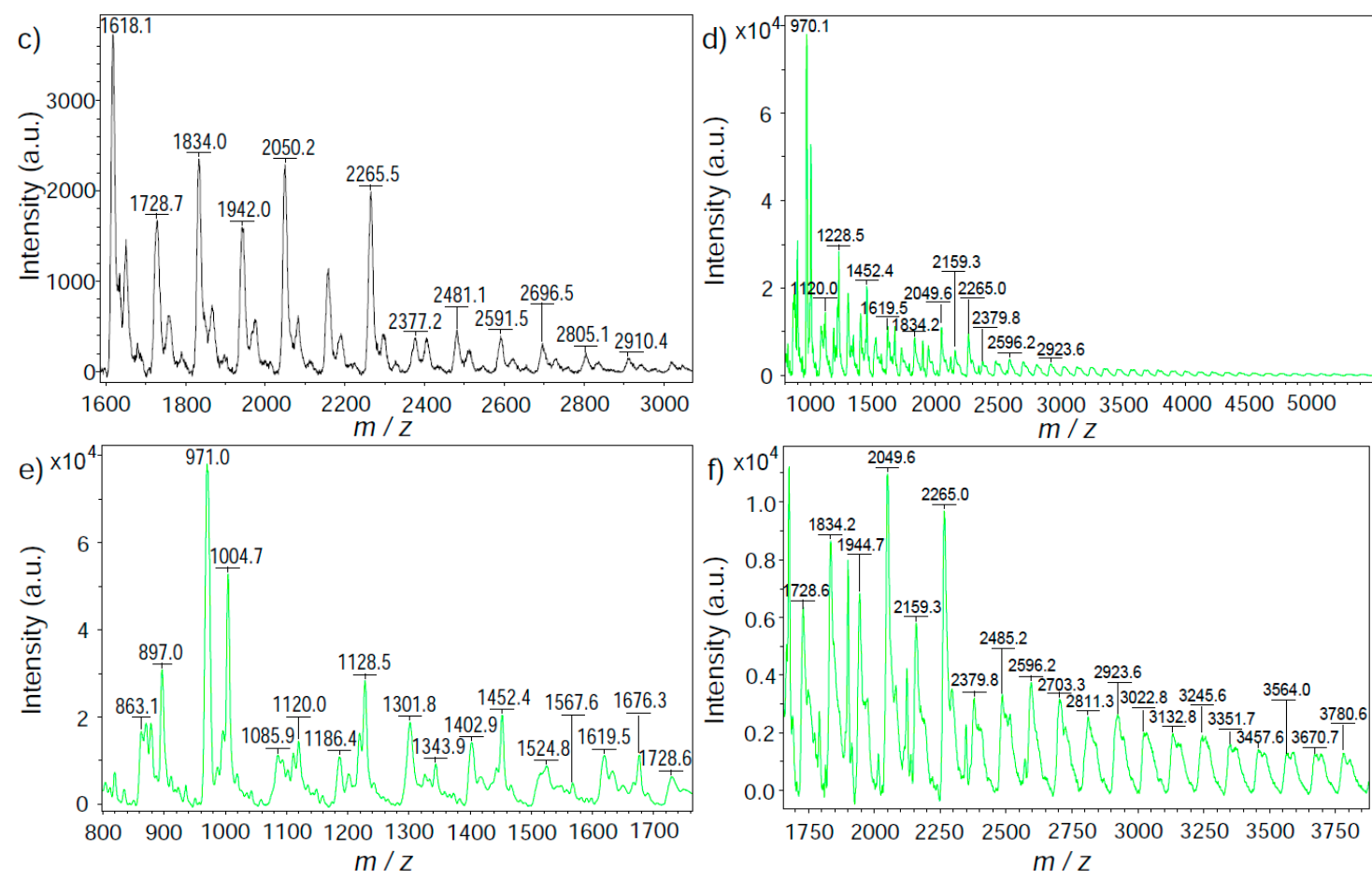

Figure 4. MALDI/TOF mass spectra of tetrahydrofuran (THF)-soluble part of PBT salts prepared with (a-c) an $\mathrm{I}_{2}$ /BT molar ratio of 1.5 and an initial BT concentration of $50 \mathrm{mmol} \mathrm{L} \mathrm{L}^{-1}$, and (d-f) an $\mathrm{H}_{2} \mathrm{O}_{2} / \mathrm{BT}$ molar ratio of 3.53 and an initial BT concentration of $58.25 \mathrm{mmol} \mathrm{L}^{-1}$ in ethanol at $25^{\circ} \mathrm{C}$ for $24 \mathrm{~h}$.

\subsubsection{XPS Analysis}

XPS analysis was initially conducted for BT monomer and PBT polymer prior to adsorption in order to characterize the available functional groups and reveal the polymerization mechanism. Figure 5 shows XPS wide scan spectra of BT, PBT, and $\mathrm{Hg}^{2+}$-loaded PBT, as well as high-resolution XPS spectra of $\mathrm{Hg} 4 \mathrm{f}, \mathrm{C} 1 \mathrm{~s}, \mathrm{~N}$ 1s, and S 2p. The XPS binding energies (BEs) obtained from the $\mathrm{Hg} 4 \mathrm{f}$, $\mathrm{C} 1 \mathrm{~s}, \mathrm{~N} 1 \mathrm{~s}$, and $\mathrm{S} 2 \mathrm{p}$ core levels, in addition to their atomic concentrations and assignments, are listed in Table 1. All of the C 1s, N 1s, and S 2p regions were analyzed by peak deconvolution. The C 1s spectrum of BT monomer was deconvoluted into three component peaks at 284.8, 286.3, and $287.5 \mathrm{eV}$, and they were attributed to adventitious carbon $(\mathrm{C}-\mathrm{C} / \mathrm{C}=\mathrm{C}), \mathrm{C}-\mathrm{N} / \mathrm{C}=\mathrm{N}$, and $\mathrm{C}-\mathrm{S} / \mathrm{C}=\mathrm{S}$, respectively (Figure 5c) [43]. The C 1s XPS of PBT polymer, however, does not clearly show significant changes of BEs in comparison with that of BT monomer, indicating that the coupling reaction of BT units does not occur on the heterocyclic carbon. The $\mathrm{N}$ 1s region of BT monomer was deconvoluted into two component peaks at 400.5 and $401.3 \mathrm{eV}$ and they were associated with $-\mathrm{N}=/ \mathrm{N}-\mathrm{N}$ and $\mathrm{N}-\mathrm{H}$, respectively (Figure 5d) [4,44]. The absence of a BE at $401.3 \mathrm{eV}$ for N-H and an apparent shift of the BE from 400.5 to $399.5 \mathrm{eV}$ for $-\mathrm{N}=/ \mathrm{N}-\mathrm{N}$ were observed in the $\mathrm{N} 1 \mathrm{~s}$ XPS spectrum of PBT polymer. This could probably be explained by the inhibition of thiol/thione or thione/thione tautomerization [8] and an increase in electron cloud density of the nitrogen atom after polymerization (Scheme 2) $[17,45,46]$. The S $2 p$ region of BT monomer was decomposed into two groups of component peaks at 162.3/163.5 eV and $164.7 / 165.8 \mathrm{eV}$, which are ascribed to $\mathrm{S}-\mathrm{H}$ and heterocyclic sulfur ( $\mathrm{C}-\mathrm{S}$ and $\mathrm{C}=\mathrm{S})$, respectively. By contrast, as can be seen from the S 2p spectrum of PBT polymer (Figure 5e), the former group of peaks at 162.3 and $163.5 \mathrm{eV}$ for S-H disappeared and the latter group of peaks at 164.7 and $165.8 \mathrm{eV}$ shifted negatively by $0.5-0.6 \mathrm{eV}$. Further, the atomic concentration of heterocyclic sulfur ( $\mathrm{C}-\mathrm{S}$ and $\mathrm{C}=\mathrm{S}$ ) and S-S groups in PBT polymer increased by about $18.6 \%$ in comparison with that in BT monomer (see Table 1). All of these confirm that the coupling of BT monomers occurs via the S-S linkage, which basically agrees with the FT-IR spectral results. 

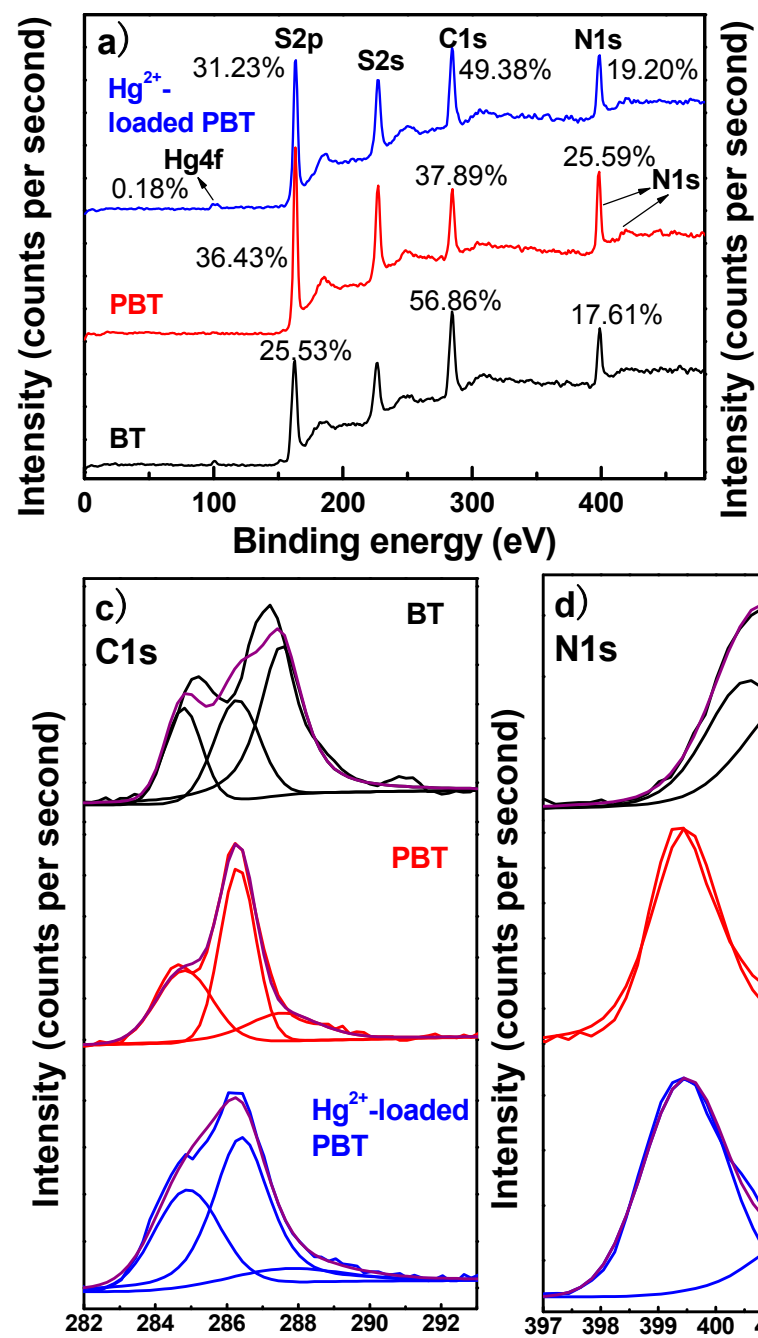

Binding energy (eV)
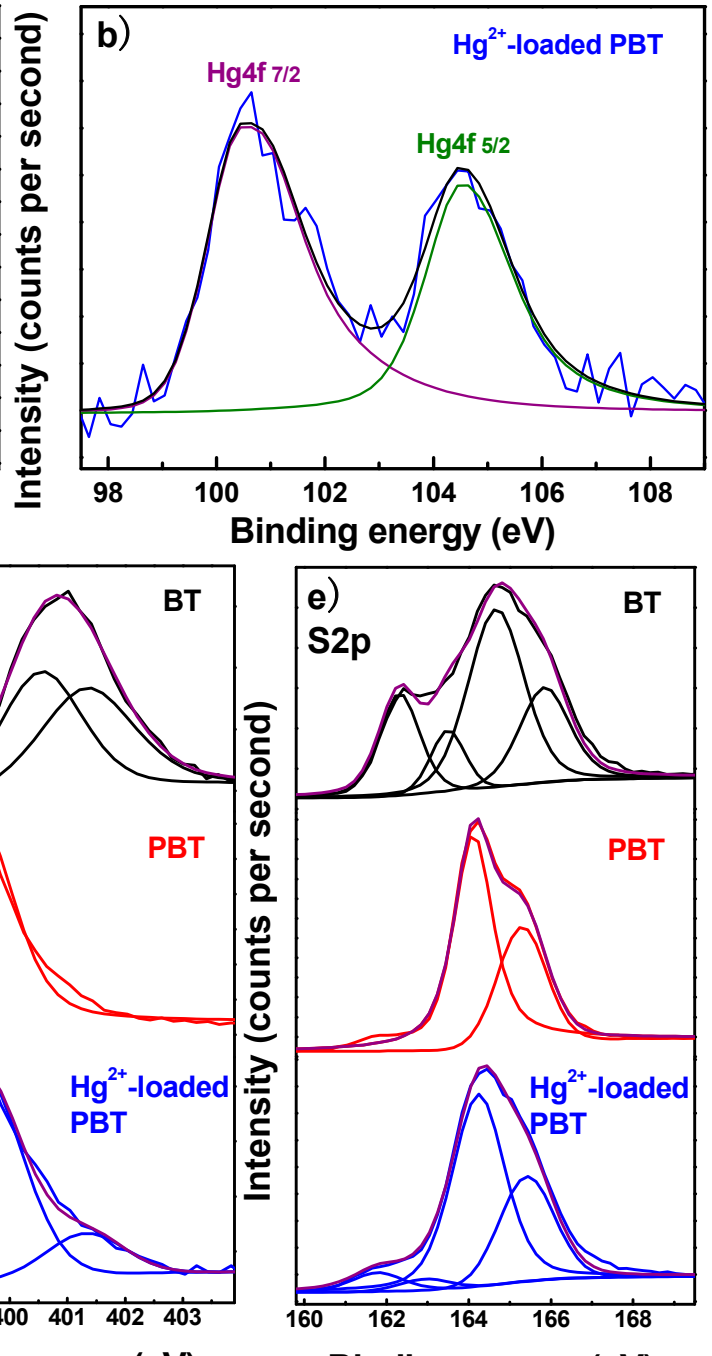

Binding energy (eV)

Figure 5. (a) XPS wide scan spectra of BT, PBT, and $\mathrm{Hg}^{2+}$-loaded PBT, and high-resolution XPS spectra of (b) $\mathrm{Hg} 4 \mathrm{f},(\mathbf{c}) \mathrm{C} 1 \mathrm{~s},(\mathbf{d}) \mathrm{N} 1 \mathrm{~s}$, and (e) S 2p.

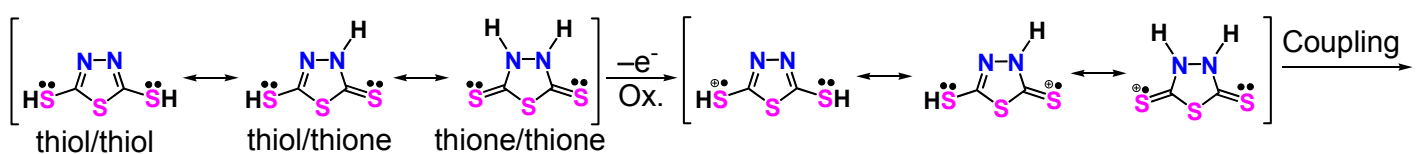

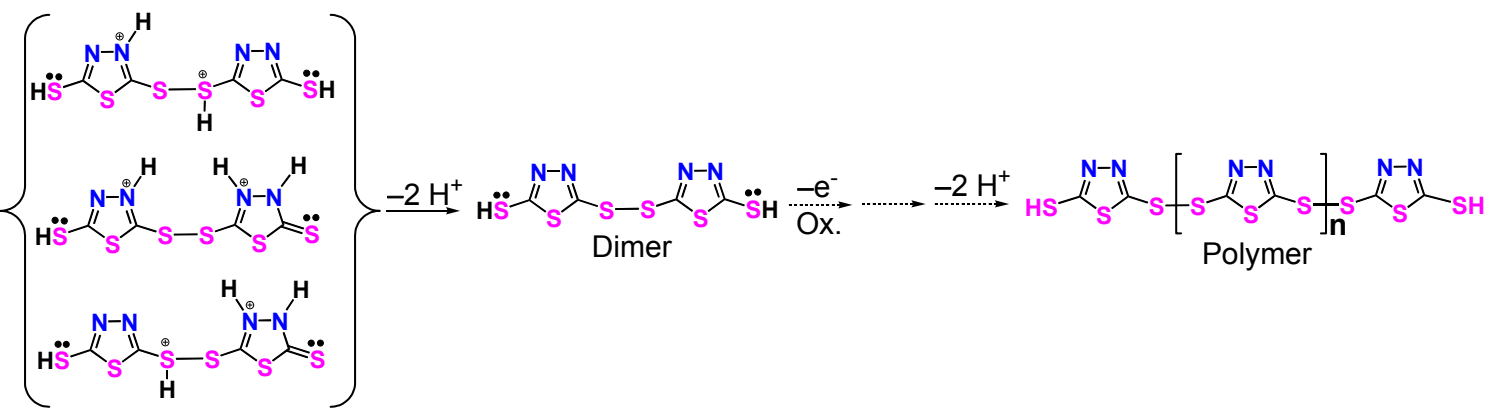

Scheme 2. Proposed polymerization mechanism of BT. 
Table 1. Assignment of main XPS spectral bands based on their binding energies (BEs) and atomic concentrations (ACs) for BT, PBT, and $\mathrm{Hg}^{2+}$-loaded PBT.

\begin{tabular}{|c|c|c|c|c|c|c|c|}
\hline \multirow{2}{*}{ Element } & \multicolumn{2}{|c|}{ BT Monomer } & \multicolumn{2}{|c|}{ PBT Polymer } & \multicolumn{2}{|c|}{ PBT-Hg ${ }^{2+}$} & \multirow{2}{*}{ Assignmentst } \\
\hline & $\mathrm{BE}(\mathrm{eV})$ & $\mathrm{AC}(\%)$ & $\mathrm{BE}(\mathrm{eV})$ & $\mathrm{AC}(\%)$ & BE $(e V)$ & $\mathrm{AC}(\%)$ & \\
\hline C $1 \mathrm{~s}$ & 284.8 & 11.6 & 284.8 & 12.0 & 284.9 & 17.5 & adventitious carbon $(\mathrm{C}-\mathrm{C}, \mathrm{C}=\mathrm{C})$ \\
\hline $\mathrm{C} 1 \mathrm{~s}$ & 286.3 & 15.2 & 286.3 & 18.8 & 286.4 & 27.6 & $\mathrm{C}-\mathrm{N}, \mathrm{C}=\mathrm{N}$ \\
\hline $\mathrm{C} 1 \mathrm{~s}$ & 287.5 & 30.0 & 287.6 & 7.1 & 287.7 & 4.3 & $C-S, C=S$ \\
\hline Total C & - & 56.86 & - & 37.89 & - & 49.38 & \\
\hline $\mathrm{N} 1 \mathrm{~s}$ & 400.5 & 8.9 & 399.5 & 25.59 & 399.5 & 16.3 & $-\mathrm{N}=, \mathrm{N}-\mathrm{N}$ \\
\hline N 1s & 401.3 & 8.8 & - & - & 401.3 & 2.9 & $\mathrm{~N}-\mathrm{H}$, or N-Hg \\
\hline Total N & - & 17.61 & - & 25.59 & - & 19.20 & \\
\hline S 2p & 162.3 & 5.2 & - & - & 161.8 & 2.0 & $\mathrm{~S}-\mathrm{H}$, or S-Hg \\
\hline$S 2 p$ & 163.5 & 2.6 & - & - & 163.0 & 1.0 & $\mathrm{~S}-\mathrm{H}$, or S-Hg \\
\hline$S 2 p$ & 164.7 & 11.9 & 164.1 & 24.3 & 164.2 & 18.9 & heterocyclic sulfur $(C-S, C=S)$, or $S-S$ \\
\hline$S 2 p$ & 165.8 & 5.9 & 165.3 & 12.1 & 165.4 & 9.4 & heterocyclic sulfur $(C-S, C=S)$, or $S-S$ \\
\hline Total S & - & 25.53 & - & 36.43 & - & 31.23 & \\
\hline $\operatorname{Hg} 4 f_{7 / 2}$ & - & - & - & - & 100.5 & 0.18 & $\mathrm{~N}-\mathrm{Hg}, \mathrm{S}-\mathrm{Hg}$ \\
\hline
\end{tabular}

\subsection{Polymerization Mechanism of PBT}

To gain a deeper insight into PBT structure and its polymerization mechanism, the proportion of frontier orbitals and the atomic electron spin density of BT monomer (Figure S2) were calculated at the B3LYP / 6-31G (d) level using Gaussian 09 software (Tables S2 and S3). The results reveal that, in the case of BT monomer, the proportions of atoms in the highest occupied molecular orbital (HOMO) (Table S2) follow the order: $\mathrm{S}(2)=\mathrm{S}(5)>\mathrm{N}(3)=\mathrm{N}(4)>\mathrm{C}(2)=\mathrm{C}(5)>>\mathrm{S}(1)$. That is to say, $\mathrm{S}(2)$ and $\mathrm{S}(5)$ atoms are more negatively charged. Since the reaction between the active molecules takes place mostly on the frontier molecular orbitals and the neighboring orbitals, it can be inferred that the coupling polymerization of BT occurs preferentially at the $S(2)$ and $S(5)$ positions. Besides, electron spin density (ESD) is another important factor determining the possibility of oxidative polymerization coupling occurring [47,48]. The ESD of BT monomer radical cations was calculated at the B3LYP/6-31G (d) level, as listed in Table S3. The results imply that $S(2)$ and S(5) atoms display the highest ESD, further signifying that $S(2)-S(5)$ coupling occurs during chemical oxidative polymerization.

Based on FT-IR, MALDI/TOF mass, XPS spectra, and theoretical calculations, one could logically draw a conclusion that the chemical oxidative polymerization of BT occurred most likely through $S(2)-S(5)$ coupling between 2- and 5-mercapto groups. This coincides well with the chemical oxidative polymerization coupling mechanism of pyrrole [49], thiophene [50], and 2-aminothiazole [40]. Therefore, we propose a polymerization mechanism of BT, as illustrated in Scheme 2. The initial step includes forming the radical cation through an electron transfer from the $\mathrm{C}-\mathrm{S}$ or $\mathrm{C}=\mathrm{S}$ moiety of $\mathrm{BT}$ tautomer to the oxidant. The next step is the reaction between the radical cations, thus forming the dication dimer, followed by a deprotonation to produce neutral dimers. The dimers can be oxidized more easily than the monomers and are thus able to form new biradical dications. Then, the as-formed biradical dication dimers would couple with either the radical cation monomers or themselves to achieve chain propagation, eventually leading to the formation of long PBT polymer chains.

\subsection{Morphological Characterization of Layered PBT Nanosheets}

Figures 6 and 7 show the SEM and TEM images of layered PBT nanosheets made with $\mathrm{H}_{2} \mathrm{O}_{2}$ and $\mathrm{I}_{2}$. The as-synthesized PBT polymers display a uniform and compact layered sheet-like morphology. The thickness of the layered PBT nanosheets made with $\mathrm{H}_{2} \mathrm{O}_{2}$ and $\mathrm{I}_{2}$ was found to be in the range $132-313 \mathrm{~nm}$ and $89-367 \mathrm{~nm}$, respectively, as shown in Figure 6. The layered morphologies of the synthesized PBTs are further characterized by TEM analysis, as depicted in Figure 7 . The layered morphologies of PBT nanosheets are clearly visible, which is consistent with the results of SEM observation. There is no deformation of the morphology of layered PBT nanosheets under the high electron beam of TEM, suggesting the stability of the synthesized layered PBT nanosheets. The formation of these layered nanosheets is related to the excessive growth, i.e., secondary growth, of the polymer and $\pi-\pi$ stacking interactions of the polymer molecular chains [51-54]. 


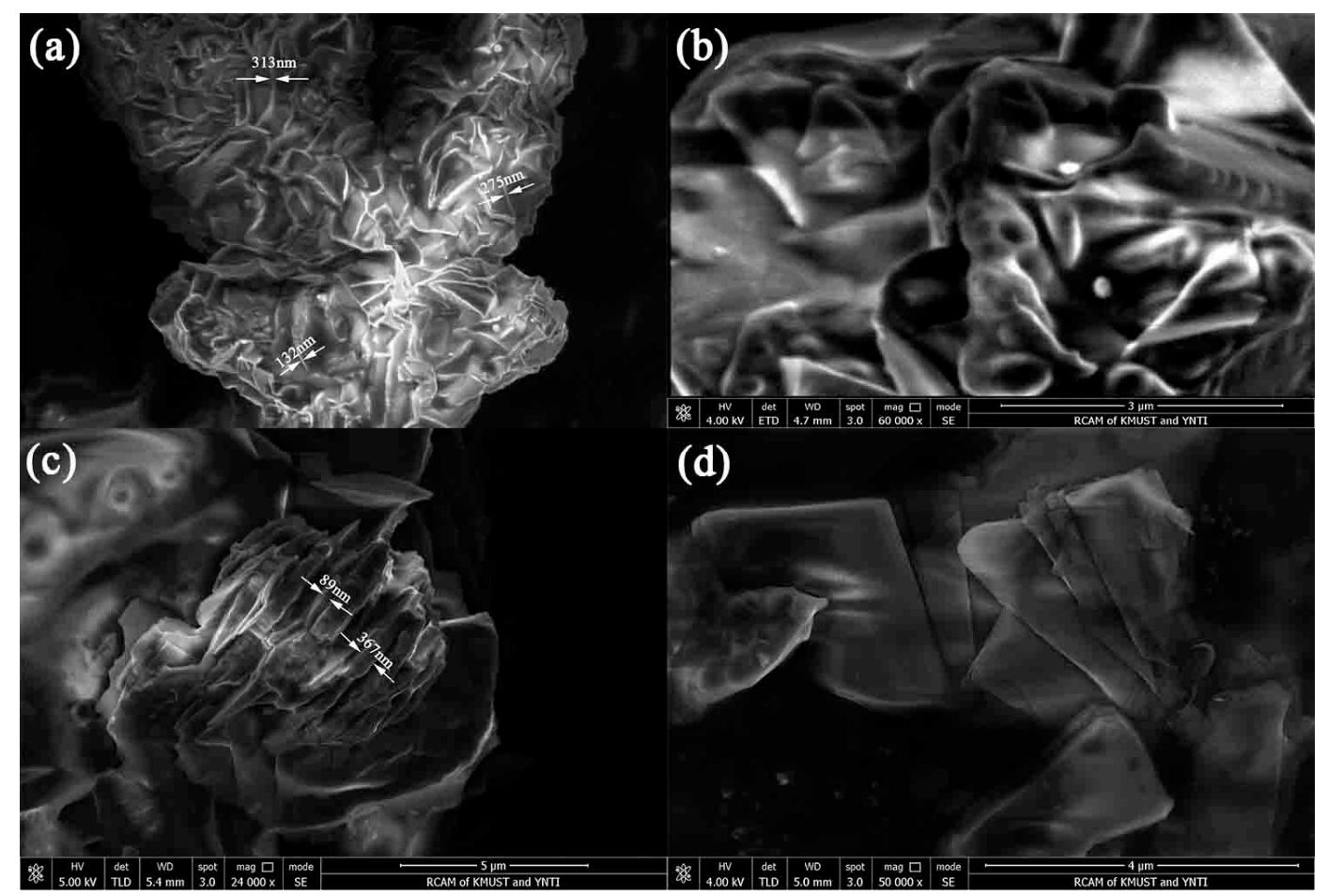

Figure 6. SEM images of PBT nanosheets synthesized with $(\mathbf{a}, \mathbf{b})$ an $\mathrm{H}_{2} \mathrm{O}_{2} / \mathrm{BT}$ molar ratio of 3.53 and an initial BT concentration of $58.25 \mathrm{mmol} \mathrm{L}^{-1}$, and (c,d) an $\mathrm{I}_{2} / \mathrm{BT}$ molar ratio of 1.5 and an initial BT concentration of $50 \mathrm{mmol} \mathrm{L}^{-1}$ in ethanol at $25^{\circ} \mathrm{C}$ for $24 \mathrm{~h}$.

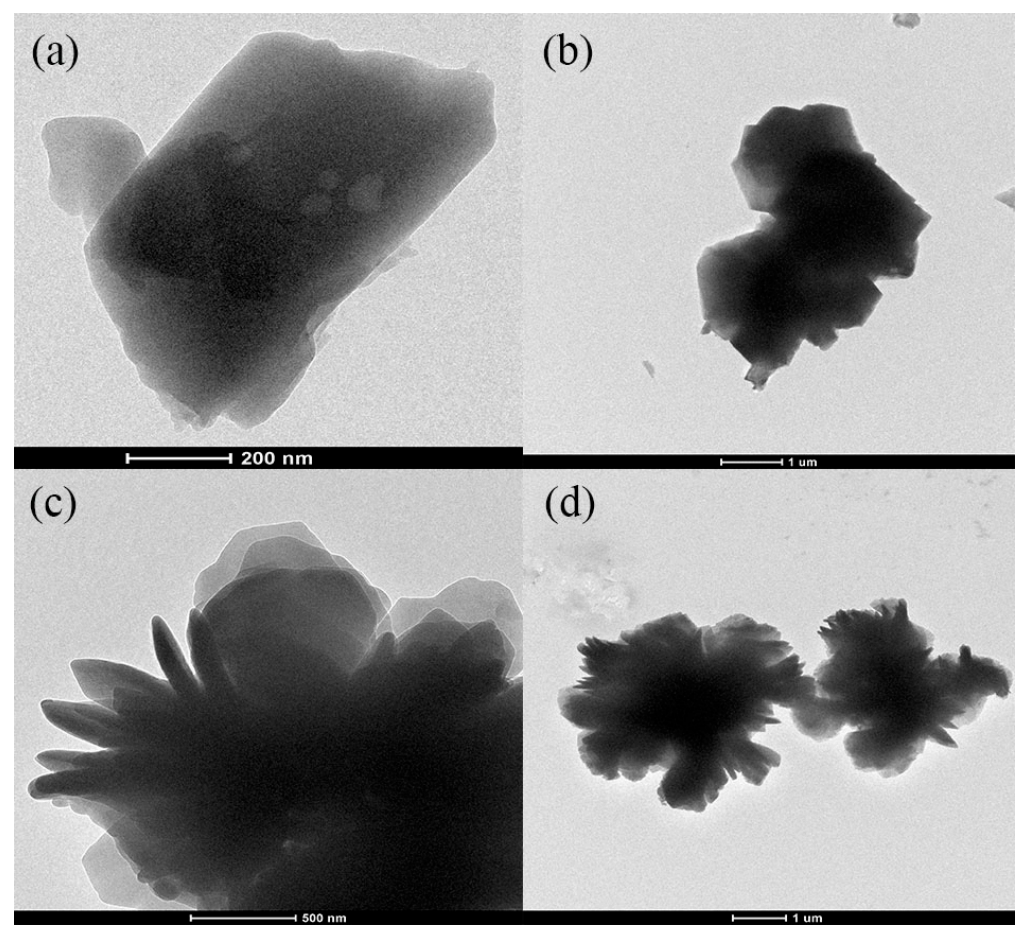

Figure 7. TEM images of PBT nanosheets synthesized with $(\mathbf{a}, \mathbf{b})$ an $\mathrm{H}_{2} \mathrm{O}_{2}$ / BT molar ratio of 3.53 and an initial BT concentration of $58.25 \mathrm{mmol} \mathrm{L}^{-1}$, and $(\mathbf{c}, \mathbf{d})$ an $\mathrm{I}_{2} / \mathrm{BT}$ molar ratio of 1.5 and an initial BT concentration of $50 \mathrm{mmol} \mathrm{L}^{-1}$ in ethanol at $25^{\circ} \mathrm{C}$ for $24 \mathrm{~h}$. 


\subsection{Properties of PBT Nanosheets}

\subsubsection{Chemical Resistance}

As summarized in Table S1, the PBT polymers demonstrate quite different chemical resistance as compared with BT monomer because the former have far higher molecular weights and thus much stronger interaction and cohesion between the macromolecular chains. The two PBT polymers are insoluble, slightly soluble, or at most partially soluble in THF, DMF, NMP, DMSO, $\mathrm{C}_{2} \mathrm{H}_{5} \mathrm{OH}, \mathrm{CH}_{3} \mathrm{OH}$, and $\mathrm{CH}_{3} \mathrm{COCH}_{3}$, but BT monomer is totally soluble in these seven solvents. The solvent resistance of the PBTs in $1 \mathrm{~mol} \mathrm{~L}^{-1} \mathrm{HCl}$ and $\mathrm{CH}_{3} \mathrm{NO}_{2}$ is also better than that of BT monomer, because the PBTs are totally insoluble in these two solvents but BT monomer is only partially or slightly soluble in them. This good chemical resistance is one of the necessary properties of PBTs for applications as excellent adsorbents, discussed below. Certainly, the PBTs and BT monomer are both completely soluble in $0.1 \mathrm{~mol} \mathrm{~L}^{-1} \mathrm{NH}_{3} \cdot \mathrm{H}_{2} \mathrm{O}$ because there are so many weakly acidic mercapto groups in PBT polymers and BT monomer.

\subsubsection{Thermostability}

Thermal analysis of the PBT polymer powder was performed using thermal gravimetric analysis (Figure 8) under a $\mathrm{N}_{2}$ atmosphere by varying the heating temperature from 30 to $1000{ }^{\circ} \mathrm{C}$ at a heating rate of $20{ }^{\circ} \mathrm{C} \mathrm{min}^{-1}$. The results show that PBT polymers have good thermostability. The PBT synthesized with $\mathrm{I}_{2}$ has no weight loss when the temperature is lower than $211^{\circ} \mathrm{C}$, and the weight loss is only $46 \mathrm{wt} \%$ at $400{ }^{\circ} \mathrm{C}$. By contrast, the PBT synthesized with $\mathrm{H}_{2} \mathrm{O}_{2}$ has no weight loss when the temperature is lower than $231{ }^{\circ} \mathrm{C}$, and the weight loss is only $42 \mathrm{wt} \%$ at $400{ }^{\circ} \mathrm{C}$. However, BT monomer could be decomposed at its melting point $\left(162{ }^{\circ} \mathrm{C}\right)$ and then lose all its weight. This implies that PBT polymers have a much higher thermal stability than BT monomer. The thermogravimetric (TG) and differential thermogravimetric (DTG) plots of PBT synthesized with $\mathrm{I}_{2}$ in Figure 8a exhibit three-stage thermal degradation at about 256,419 , and $691{ }^{\circ} \mathrm{C}$, indicating that the polymer decomposition takes place in three steps. The first step $\left(211-311^{\circ} \mathrm{C}\right)$ with a $T_{\mathrm{DTG}}$ of $256^{\circ} \mathrm{C}$ shows a weight loss of $24.4 \%$, which should be caused by the exclusion of the residual dopant, the oxidant and its reduced product trapped in the samples, the end-mercapto groups, and a small part of oligomers [30]. The second step $\left(311-566{ }^{\circ} \mathrm{C}\right.$ ) with a $T_{\text {DTG }}$ of $419{ }^{\circ} \mathrm{C}$ exhibits a major loss of $48.7 \%$ owing to the gradual decomposition of the polymer backbones. The third step $\left(566-768^{\circ} \mathrm{C}\right)$ with a $T_{\mathrm{DTG}}$ of $691^{\circ} \mathrm{C}$ presents a $23.5 \%$ weight loss due to the further pyrolysis of residual char formed after the initial PBT decomposition [55]. Similarly, the PBT synthesized with $\mathrm{H}_{2} \mathrm{O}_{2}$ also presents three-step decomposition at $267^{\circ} \mathrm{C}\left(231-331^{\circ} \mathrm{C}\right), 424{ }^{\circ} \mathrm{C}\left(331-586^{\circ} \mathrm{C}\right)$, and $710{ }^{\circ} \mathrm{C}\left(586-786^{\circ} \mathrm{C}\right)$ (Figure 8b), showing a weight loss of $26.3 \%, 45.8 \%$, and $24.2 \%$, respectively. The differential scanning calorimetry (DSC) plots reveal that PBT polymers synthesized with $\mathrm{I}_{2}$ and $\mathrm{H}_{2} \mathrm{O}_{2}$ display an endothermic peak at $176{ }^{\circ} \mathrm{C}$ and $216{ }^{\circ} \mathrm{C}$, respectively, probably originating from the melting of a small part of the BT oligomers [32], since they show no weight loss at the transition temperature. So, these two PBT polymers are possibly suitable for various thermoforming processing. The strongest endothermic peak at $717-718^{\circ} \mathrm{C}$ with a heat flow of $0.95-1.14 \mathrm{~mW} \mathrm{mg}^{-1}$ shown in the DSC plots is ascribed to the pyrolysis of residual char in the third step. The DSC behavior of PBT polymers differs significantly from that of the coordination polymer 2,5-dimercapto-1,3,4-thiadiazole-gold, which exhibits four peaks at 280, 510, 600, and $730{ }^{\circ} \mathrm{C}$ and begins to decompose at $260^{\circ} \mathrm{C}$ due to the cleavage of metal-sulphur and metal-nitrogen linkages [17]. 

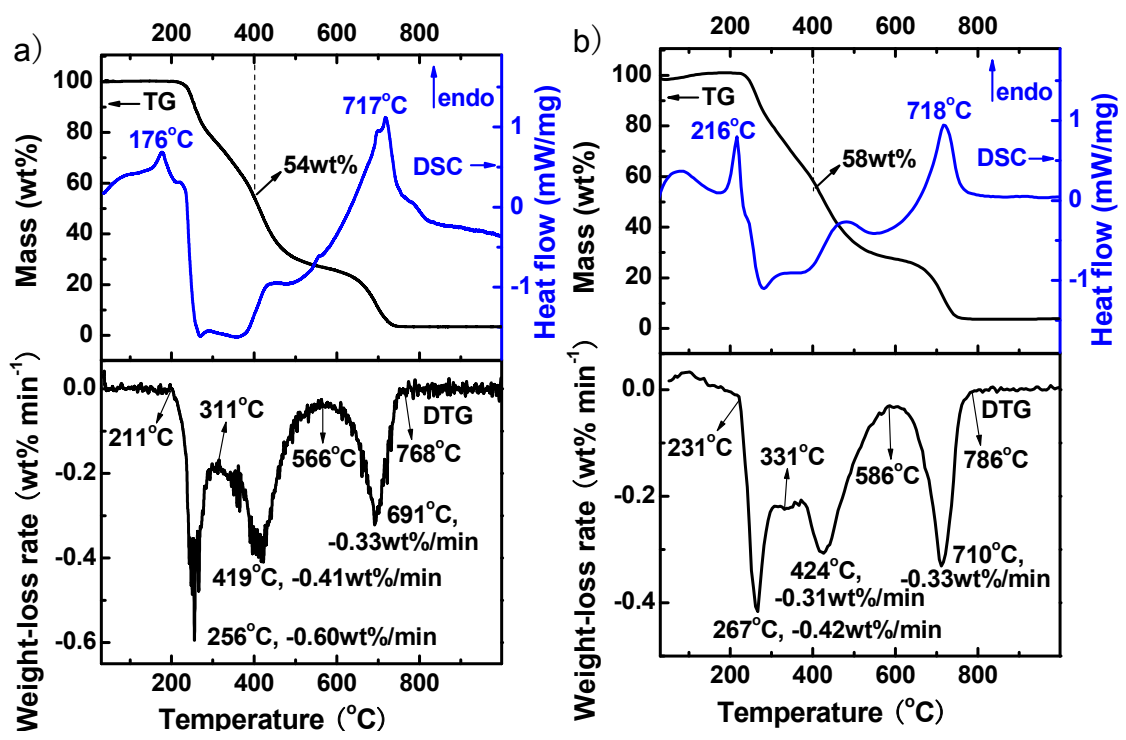

Figure 8. Thermogravimetry (TG), differential thermogravimetry (DTG), and differential scanning calorimetry (DSC) curves in nitrogen for PBT powder prepared with (a) $\mathrm{I}_{2}$ and (b) $\mathrm{H}_{2} \mathrm{O}_{2}$.

\subsubsection{Fluorescence Properties}

The fluorescent excitation and emission spectra of BT monomer and PBT nanosheets synthesized with two oxidants in Figure 9 suggest that all of the PBT polymers and BT monomer exhibited analogous excitation and emission spectra, with similar shapes and peak positions. All the excitation spectra show a broad peak centered at about $367-368 \mathrm{~nm}$, owning to $\mathrm{n} \rightarrow \pi^{*}$ electronic transitions found in both BT monomer and its polymers. In the case of PBT polymers, both the emission spectra generated by the radiative decay of excitons exhibit a maximal peak at $454-456 \mathrm{~nm}$, suggesting that the PBT nanosheets are typical blue-light emitting materials. Note that PBT polymers emit relatively longer wavelength fluorescence than BT monomer due to the polymerization effect. Meanwhile, PBT polymer synthesized with $\mathrm{I}_{2}$ shows almost equivalent fluorescence emission intensity but slightly longer emission wavelength in comparison with that synthesized with $\mathrm{H}_{2} \mathrm{O}_{2}$. Hence, we choose PBT polymer synthesized with $\mathrm{I}_{2}$ for the latter fluorescence investigation.

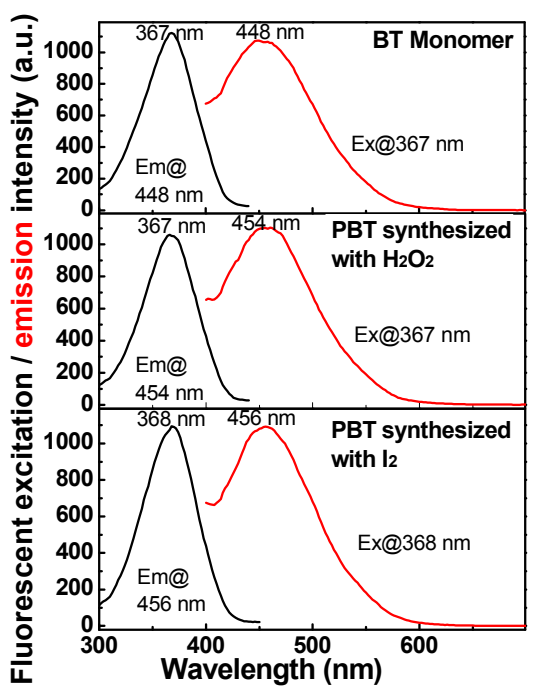

Figure 9. Fluorescent excitation and emission spectra obtained at fixed slit widths of $5 \mathrm{~nm}$ of $100 \mu \mathrm{g} \mathrm{L}^{-1} \mathrm{BT}$ and PBT solutions in N-methy1-2-pyrrolidone (NMP). 
Also, the fluorescence emission intensity of PBT solution depends markedly on its concentration (Figure S3), with the fluorescence emission culminating at $50 \mu \mathrm{g} \mathrm{L}^{-1}$ when excited at $368 \mathrm{~nm}$, because an increased PBT concentration within a certain range would enhance the fluorophore concentration and thus the fluorescence intensity, but further increasing the PBT concentration from $50 \mu \mathrm{g} \mathrm{L}$ to $200 \mu \mathrm{g} \mathrm{L} \mathrm{L}^{-1}$ would cause self-absorption and self-quenching effects and thereby weaken the fluorescence emission. Therefore, a PBT concentration of $50 \mu \mathrm{g} \mathrm{L}{ }^{-1}$ was chosen for the subsequent fluorescence investigation.

When maintaining the other fluorescence spectrum examination conditions unchanged except to replace the solvent pure NMP with semi-aqueous $\mathrm{NMP} / \mathrm{H}_{2} \mathrm{O}(9: 1, v / v)$, the optimal excitation wavelength, relative fluorescence intensity, and profiles of excitation and emission spectra underwent almost no change or insignificant change, though the emission maximum exhibited a blue shift from $456 \mathrm{~nm}$ to $443 \mathrm{~nm}$. This signifies that the existence of a little water in the test solution may have a negligible effect on the fluorescence emission. Thus, the PBT fluorescent probe can be a candidate for the direct detection of metal ions in water. Figure 10a,b show the fluorescence emission spectra and intensity changes of the reaction mixtures of the PBT-NMP solution with different metal ions in an aqueous solution or pure water (blank). Interestingly, the fluorescence of PBT was enhanced without exception after reacting with any kind of metal ion. The fluorescence enhancement is attributed to the inhibition of the photoinduced electron transfer (PET) quenching of the excited state of the fluorophore moiety, i.e., the 1,3,4-thiadiazole ring (electron acceptor), by the lone pair electrons of $S(2)$ or $S(5)$ atoms (electron donor) [56-58].
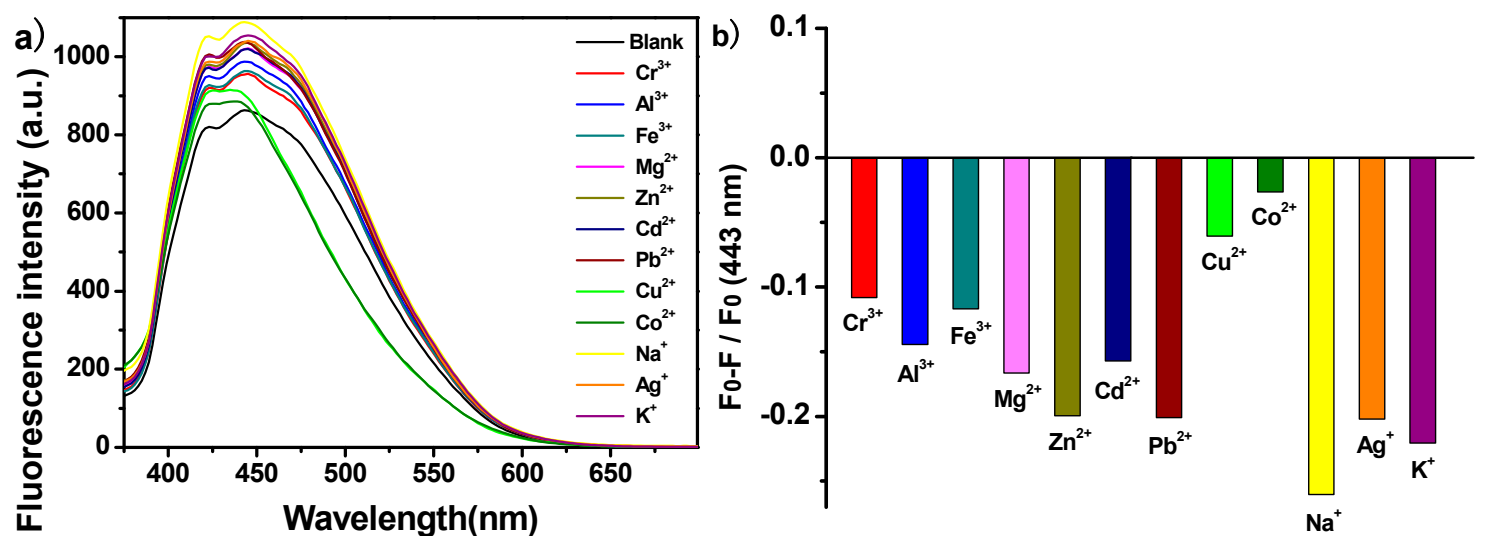

Figure 10. (a) Fluorescence spectra of PBT $(50 \mu \mathrm{g} \mathrm{L}-1)$ in the absence (blank) and presence of different metal salts $\left(1.0 \times 10^{-5} \mathrm{~mol} \mathrm{~L}^{-1}\right)$ recorded in an $\mathrm{NMP} / \mathrm{H}_{2} \mathrm{O}(9: 1, v / v)$ solvent system at $\mathrm{pH} 7.0$, excitation wavelength is $350 \mathrm{~nm}$; (b) fluorescence intensity change plot for PBT where $\left(F_{0}-F\right) / F_{0}$ is plotted against each metal ion $\left(F_{0}\right.$ is the fluorescence intensity in the absence of metal ions, and $F$ is the intensity when metal ions are present).

\subsubsection{Adsorption of Heavy Metal Ions}

\section{Adsorption Capacity}

The PBT nanosheets obtained by $\mathrm{I}_{2}$ and $\mathrm{H}_{2} \mathrm{O}_{2}$ exhibit a powerful adsorbability toward heavy metal ions because of the presence of a large amount of $-\mathrm{S}-,-\mathrm{SH}$, and $=\mathrm{N}-$ groups containing lone pairs of electrons on the PBT chains that are confirmed by the FT-IR and MALDI-TOF mass spectroscopies. The result of the preliminary adsorption experiment shows that when the initial $\mathrm{Pb}^{2+}$ concentration was up to $200 \mathrm{mg} \mathrm{L}^{-1}$ and the dosage of PBT sorbent was $1.0 \mathrm{~g} \mathrm{~L}^{-1}$, the adsorption capacities and adsorption ratios toward $\mathrm{Pb}^{2+}$ ion for PBT nanosheets obtained by $\mathrm{I}_{2}$ and $\mathrm{H}_{2} \mathrm{O}_{2}$ were 168.23 and $124.56 \mathrm{mg} \mathrm{g}^{-1}$, and $75.18 \%$ and $65.27 \%$, respectively. It is clear that the PBT obtained with $\mathrm{I}_{2}$ exhibits better adsorption performance than that obtained with $\mathrm{H}_{2} \mathrm{O}_{2}$, so the PBT obtained with $\mathrm{I}_{2}$ was chosen for the further study of heavy metal ion adsorption. 
To investigate the adsorption capacity of PBT nanosheets, several heavy metal ions including $\mathrm{Hg}^{2+}, \mathrm{Pb}^{2+}, \mathrm{Ag}^{+}, \mathrm{Co}^{2+}, \mathrm{Cr}^{3+}, \mathrm{Cd}^{2+}, \mathrm{Fe}^{3+}, \mathrm{Zn}^{2+}$, and $\mathrm{Cu}^{2+}$ at the same concentrations of $200 \mathrm{mg} \mathrm{L}^{-1}$ were used for adsorption testing, and the experiments were conducted by batch test. The results are summarized in Table 2, from which one can find that the PBT nanosheets exhibited excellent adsorption capacity $(Q)$ for most metal ions, with the $Q$ values following the order: $Q\left(\mathrm{Hg}^{2+}\right)>Q\left(\mathrm{~Pb}^{2+}\right)>Q\left(\mathrm{Ag}^{+}\right)>Q\left(\mathrm{Fe}^{3+}\right)>Q\left(\mathrm{Cu}^{2+}\right)>Q\left(\mathrm{Cd}^{2+}\right)>\mathrm{Q}\left(\mathrm{Zn}^{2+}\right)>Q\left(\mathrm{Co}^{2+}\right)>Q\left(\mathrm{Cr}^{3+}\right)$. The highest adsorption capacity for $\mathrm{Hg}^{2+}$ ion was found up to $168.23 \mathrm{mg} \mathrm{g}^{-1}\left(0.84 \mathrm{mmol} \mathrm{g}^{-1}\right)$. The polyfunctional groups including $-\mathrm{S}_{-},-\mathrm{SH}$, and $=\mathrm{N}-$ could efficiently bind metal ions through sharing lone pairs of electrons to form chelating bonds (Scheme 1), which explains why the PBT nanosheets exhibited such good adsorption capacities.

Table 2. Adsorption capacity and adsorption ratio of nine metal ions at an initial metal concentration of $200 \mathrm{mg} \mathrm{L}^{-1}$ and an adsorption temperature of $25^{\circ} \mathrm{C}$ for a contact time of $24 \mathrm{~h}$ with a PBT sorbent dosage of $1.0 \mathrm{~g} \mathrm{~L}^{-1}$.

\begin{tabular}{|c|c|c|c|c|c|}
\hline \multirow{2}{*}{$\begin{array}{l}\text { Metal Ion } \\
\text { Solutions }\end{array}$} & \multirow{2}{*}{$\begin{array}{c}\text { Adsorption } \\
\text { Capacity }\left(\mathrm{mg} \mathrm{g}^{-1}\right)\end{array}$} & \multirow{2}{*}{$\begin{array}{l}\text { Adsorption } \\
\text { Ratio (\%) }\end{array}$} & \multicolumn{3}{|c|}{ Theoretical Selectivity Coefficien } \\
\hline & & & $\mathrm{Hg}^{2+}$ & $\mathrm{Pb}^{2+}$ & $\mathrm{Ag}^{+}$ \\
\hline $\mathrm{Hg}\left(\mathrm{NO}_{3}\right)_{2}$ & 168.23 & 84.12 & 1.00 & 0.89 & 0.43 \\
\hline $\mathrm{Pb}\left(\mathrm{NO}_{3}\right)_{2}$ & 149.77 & 75.18 & 1.12 & 1.00 & 0.48 \\
\hline $\mathrm{AgNO}_{3}$ & 71.87 & 36.29 & 2.34 & 2.08 & 1.00 \\
\hline $\mathrm{Co}\left(\mathrm{NO}_{3}\right)_{2}$ & 28.22 & 14.36 & 5.96 & 5.31 & 2.55 \\
\hline $\mathrm{Cr}\left(\mathrm{NO}_{3}\right)_{3}$ & 22.89 & 11.47 & 7.35 & 6.54 & 3.14 \\
\hline $\mathrm{Cd}\left(\mathrm{NO}_{3}\right)_{2}$ & 42.35 & 21.46 & 3.97 & 3.54 & 1.70 \\
\hline $\mathrm{Fe}\left(\mathrm{NO}_{3}\right)_{3}$ & 53.27 & 30.12 & 3.16 & 2.81 & 1.35 \\
\hline $\mathrm{Zn}\left(\mathrm{NO}_{3}\right)_{2}$ & 36.22 & 18.13 & 4.64 & 4.14 & 1.98 \\
\hline $\mathrm{Cu}(\mathrm{NO})_{2}$ & 50.30 & 25.15 & 3.34 & 2.98 & 1.43 \\
\hline
\end{tabular}

Competitive Adsorption of Metal Ions

As summarized in Table 2, the theoretical selectivity coefficients of three heavier $\mathrm{Hg}^{2+}, \mathrm{Pb}^{2+}$, and $\mathrm{Ag}^{+}$ions versus six lighter ions range from 1.35 to 7.35 , signifying that coexisting lighter ions cannot greatly influence the robust adsorbability of PBT nanosheets toward heavier $\mathrm{Hg}^{2+}$ and $\mathrm{Ag}^{+}$ions, as shown in Table 3. The adsorption ratio $(q, \%)$ order onto the nanosheets was $\mathrm{Hg}^{2+}>\mathrm{Ag}^{+}>\mathrm{Fe}^{3+}>\mathrm{Cu}^{2+}>\mathrm{Cr}^{3+}>\mathrm{Co}^{2+}>\mathrm{Cd}^{2+}>\mathrm{Zn}^{2+}>\mathrm{Pb}^{2+}$. The most powerful adsorbability of $\mathrm{Hg}^{2+}$ and $\mathrm{Ag}^{+}$ions onto the nanosheets was not significantly affected by the seven coexisting metal ions, while the adsorbability of $\mathrm{Pb}^{2+}$ was at a disadvantage in the competitive adsorption. The results of selectivity experiments imply that PBT nanosheets showed stronger affinity to $\mathrm{Hg}^{2+}$ and $\mathrm{Ag}^{+}$ions rather than $\mathrm{Fe}^{3+}, \mathrm{Cu}^{2+}, \mathrm{Cr}^{3+}, \mathrm{Co}^{2+}, \mathrm{Cd}^{2+}, \mathrm{Zn}^{2+}$, and $\mathrm{Pb}^{2+}$ ions in competitive adsorption systems. According to the soft and hard acids and bases (SHAB) theory $[59,60], \mathrm{Hg}^{2+}$ and $\mathrm{Ag}^{+}$are classified as soft acids, and the $-\mathrm{S}-,-\mathrm{SH}$, and $=\mathrm{N}-$ groups behave as soft bases. This explains why the basic PBT nanosheets preferentially adsorb the acidic metal ions such as $\mathrm{Hg}^{2+}$ and $\mathrm{Ag}^{+}$.

Table 3. Competitive adsorption of nine metal ions onto $50 \mathrm{mg}$ of PBT at $25^{\circ} \mathrm{C}$ in $50 \mathrm{~mL}$ solution at the same initial ion concentration of $20 \mathrm{mg} \mathrm{L}^{-1}$ for each metal ion for $24 \mathrm{~h}$.

\begin{tabular}{cccc}
\hline Mixed Solution & Metal Ions & Adsorption Capacity $\left(\mathrm{mg} \mathrm{g}^{-\mathbf{1}}\right)$ & Adsorption Ratio (\%) \\
\hline $\mathrm{Hg}\left(\mathrm{NO}_{3}\right)_{2}$ & $\mathrm{Hg}^{2+}$ & 19.22 & 98.38 \\
$\mathrm{~Pb}\left(\mathrm{NO}_{3}\right)_{2}$ & $\mathrm{~Pb}^{2+}$ & 10.38 & 53.13 \\
$\mathrm{AgNO}$ & $\mathrm{Ag}_{3}$ & 17.00 & 87.06 \\
$\mathrm{Co}\left(\mathrm{NO}_{3}\right)_{2}$ & $\mathrm{Co}^{2+}$ & 11.72 & 60.01 \\
$\mathrm{Cr}\left(\mathrm{NO}_{3}\right)_{3}$ & $\mathrm{Cr}^{3+}$ & 11.78 & 60.30 \\
$\mathrm{Cd}\left(\mathrm{NO}_{3}\right)_{2}$ & $\mathrm{Cd}^{2+}$ & 11.32 & 57.96 \\
$\mathrm{Fe}\left(\mathrm{NO}_{3}\right)_{3}$ & $\mathrm{Fe}^{3+}$ & 12.33 & 63.11 \\
$\mathrm{Zn}\left(\mathrm{NO}_{3}\right)_{2}$ & $\mathrm{Zn}^{2+}$ & 11.11 & 56.88 \\
$\mathrm{Cu}\left(\mathrm{NO}_{2}\right.$ & $\mathrm{Cu}^{2+}$ & 12.11 & 61.99 \\
\hline
\end{tabular}




\section{Adsorption Kinetics}

The adsorption kinetics of PBT nano-sorbent was studied using $\mathrm{Hg}^{2+}$ as a target analyte. The effect of variation of the initial $\mathrm{Hg}^{2+}$ concentration on the adsorption capacity and adsorption ratio by PBT nanosheets is shown in Figure 11. The initial $\mathrm{Hg}^{2+}$ concentration was varied from $10 \mathrm{mg} \mathrm{L}^{-1}$ to $2000 \mathrm{mg} \mathrm{L}^{-1}$ and equilibrated for $24 \mathrm{~h}$ at a fixed sorbent dose of PBT. It is apparent that the adsorption capacity of $\mathrm{Hg}^{2+}$ ion by $\mathrm{PBT}$ nanosheets increased with increasing $\mathrm{Hg}^{2+}$ concentration, but the adsorption ratio behaved in the opposite way. At a lower concentration, $\mathrm{Hg}^{2+}$ ions in the aqueous solution would interact with the binding sites but the binding sites were ultimately unsaturated, thus facilitating an adsorption ratio of $93 \%$ but an adsorption capacity of only $9.30 \mathrm{mg} \mathrm{g}^{-1}$. At higher concentrations, more $\mathrm{Hg}^{2+}$ ions are left unadsorbed in the solution because of the saturation of the binding sites, resulting in a decreased adsorption ratio but increased adsorption capacity. This indicates that energetically less favorable sites become involved with increasing ion concentrations in an aqueous solution [61]. Notably, the highest adsorption capacity can reach up to $680.01 \mathrm{mg} \mathrm{g}^{-1}$ (3.39 mmol g${ }^{-1}$ ), which is much higher than that for most polymer sorbents [62-65].

The rate at which adsorption takes place is most important when the adsorbent is employed for actual sewage treatment. Consequently, it is important to establish the contact time dependence of such an adsorbent adsorbing $\mathrm{Hg}^{2+}$ ions. Figure 12 shows the plot of $\mathrm{Hg}^{2+}$ adsorbance and adsorption ratio versus contact time onto the PBT nanosheets obtained by $\mathrm{I}_{2}$ to investigate the adsorption kinetics and discover the time of reaching equilibrium adsorption. The adsorption takes place very rapidly within the initial $5 \mathrm{~min}$. The $\mathrm{Hg}^{2+}$ adsorption capacity and adsorption ratio at an adsorption time of $5 \mathrm{~min}$ are even as high as $154.27 \mathrm{mg} \mathrm{g}^{-1}$ and $77.14 \%$, respectively, which are $91.7 \%$ of those at the equilibrium adsorption. However, the adsorption slows down after $5 \mathrm{~min}$. It was revealed that the adsorption process comprises two steps, i.e., an initial primary rapid step and a subsequent secondary slow step [33]. Correspondingly, the rapid adsorption should take place on the nanosheet surfaces due to the immediate chelation between the $\mathrm{Hg}^{2+}$ ions and exposed active sites of the PBT chains. In contrast, the slow step may occur inside the nanosheets, representing the diffusion of the $\mathrm{Hg}^{2+}$ ions into the interior of the nanosheets. The electrostatic repulsion between the free and adsorbed $\mathrm{Hg}^{2+}$ ions on the surface of nanosheets makes it difficult for free and bulky mercury ions to enter into the interior of the nanosheets.

To gain a deep insight into the adsorption kinetics of the removal of $\mathrm{Hg}^{2+}$ by PBT adsorbent, the experimental data were fitted into the pseudo-first-order and pseudo-second-order kinetics equations $[66,67]$. The curves regarding the equations of $-\ln \left(1-Q_{\mathrm{t}} / Q_{\mathrm{e}}\right)=k_{1} t$ and $t / Q_{\mathrm{t}}=t / Q_{\mathrm{e}}+1 / h_{0}$ in the inset of Figure 12 produce relevant parameters including rate constants and correlation coefficients, as shown in Table 4 . The correlation coefficient, $R^{2}$, showed that the pseudo-second-order kinetic model, an indication of chemisorption mechanism, fits better with the experimental data than the pseudo-first-order kinetic model. Thus, the adsorption can be well interpreted as a chemisorption process based on the assumption of the rate determining step comprising the formation of coordination bonds between the sorbent and adsorbate, in addition to surface adsorption and intraparticle diffusion [61]. Amazingly, it was found that the adsorption time at equilibrium is even shorter, down to $1.0 \mathrm{~h}$ for $\mathrm{Hg}^{2+}$. Furthermore, the PBT adsorbents show very rapid initial adsorption rates with a rate constant $h_{0}$ of up to $10,653 \mathrm{mg} \mathrm{g}^{-1} \mathrm{~h}^{-1}$ according to the pseudo-second-order kinetics. No higher $h_{0}$ value than this could be found in the literature $[62,68,69]$. Such a rapid adsorption is due to a great number of various electron-rich groups including $-\mathrm{S}-,-\mathrm{SH}$, and $=\mathrm{N}-$ on the PBT nanosheets, as well as their high porosity which is confirmed by the low density (apparent density, $0.521 \mathrm{~g} \mathrm{~cm}^{-3}$; bulk density, $\left.0.813 \mathrm{~g} \mathrm{~cm}^{-3}\right)$ and moderate specific area $\left(15.85 \mathrm{~m}^{2} \mathrm{~g}^{-1}\right)$ in Figure S4 of the Supplementary Materials. 


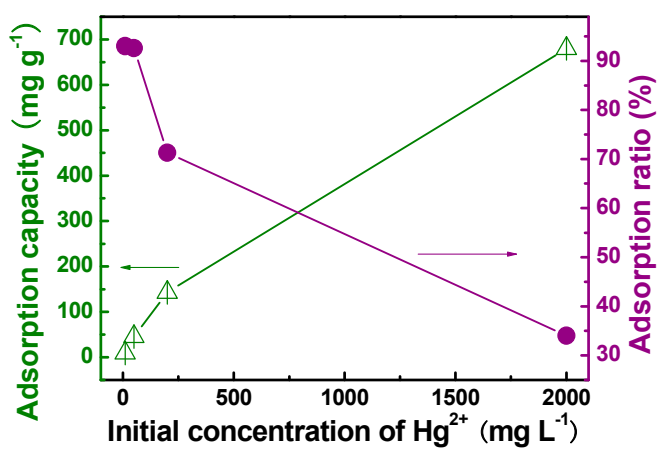

Figure 11. Adsorption capacity and adsorption ratio of $\mathrm{Hg}^{2+}$ onto $50 \mathrm{mg}$ of $\mathrm{PBT}$ at $25^{\circ} \mathrm{C}$ in $50 \mathrm{~mL}$ solution at different initial ion concentrations for $24 \mathrm{~h}$.

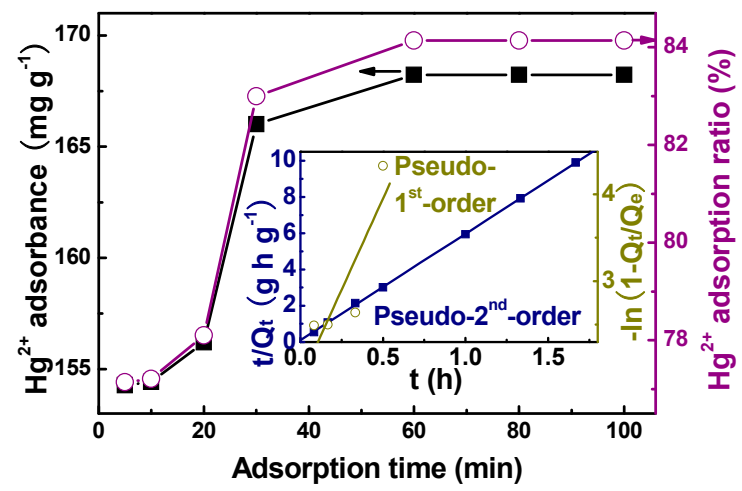

Figure 12. Adsorption kinetics of $\mathrm{Hg}^{2+}$ ions onto PBT nanosheets.

Table 4. Kinetic model equations for $\mathrm{Hg}^{2+}$ adsorption onto PBT nanosheets.

\begin{tabular}{|c|c|c|c|c|c|c|}
\hline \multirow[b]{2}{*}{ Mathematical Model } & \multirow[b]{2}{*}{ Equation } & \multirow[b]{2}{*}{$R^{2}$} & \multirow{2}{*}{$\begin{array}{l}\text { Standard } \\
\text { Deviation }\end{array}$} & \multirow{2}{*}{$\begin{array}{c}k_{1}\left(\mathrm{~h}^{-1}\right) \\
k_{2}\left(\mathrm{~g} \mathrm{mg}^{-1} \mathrm{~h}^{-1}\right) \\
h_{0}=k_{2} Q_{\mathrm{e}^{2}}\left(\mathrm{mg} \mathrm{g}^{-1} \mathrm{~h}^{-1}\right)\end{array}$} & \multicolumn{2}{|c|}{$Q_{\mathrm{e}}$ Found by } \\
\hline & & & & & Experiment & Equation \\
\hline Pseudo-1st-order & $-\ln \left(1-Q_{\mathrm{t}} / Q_{\mathrm{e}}\right)=4.1913 t+1.8535$ & 0.7491 & 0.5490 & $k_{1}=4.1913$ & 168.23 & - \\
\hline Pseudo-2nd-order & $t / Q_{\mathrm{t}}=0.00588 t+9.3872 \times 10^{-5}$ & 0.9988 & $4.4622 \times 10^{-5}$ & $\begin{array}{c}k_{2}=0.3764 \\
h_{0}=1.0653 \times 10^{4}\end{array}$ & 168.23 & 170.07 \\
\hline
\end{tabular}

\section{Adsorption Mechanism}

The adsorption mechanism of PBT nanosheets for $\mathrm{Hg}^{2+}$ was further studied by XPS spectral analysis (Figure 5). Several strong peaks with BEs of 163.2, 284.7, and $398.4 \mathrm{eV}$ correspond to S 2p, C 1s, and $\mathrm{N}$ 1s orbitals, respectively, which exist in pristine PBT nanosheets (Figure 5a). Upon adsorbing $\mathrm{Hg}^{2+}$ ions, a new shoulder peak with a BE of approximately 99.6-102.8 eV appears (Figure 5a,b), which confirms that $\mathrm{Hg}^{2+}$ ions were adsorbed onto PBT nanosheets. The high-resolution XPS spectra of $\mathrm{C} 1 \mathrm{~s}, \mathrm{~N} 1 \mathrm{~s}$, and $\mathrm{S} 2 \mathrm{p}$ core levels are shown in Figure $5 \mathrm{c}-\mathrm{e}$, and the corresponding BEs are summarized in Table 1. The high-resolution C 1s XPS spectrum of PBT exhibited negligible changes after the adsorption of $\mathrm{Hg}^{2+}$ (Figure $5 \mathrm{c}$ ), indicating that carbon atoms were not involved in the adsorption of mercury. By contrast, both the high-resolution XPS spectra of N 1s and S 2p for PBT presented a new group of bands with BEs of 401.3 and $161.8 / 163.0 \mathrm{eV}$ after the adsorption of mercury, respectively, which are respectively attributed to $\mathrm{N}-\mathrm{Hg}$ and $\mathrm{S}-\mathrm{Hg}$ coordination bonds, not discarding the possibility of the existence of protonated nitrogen and sulfur atoms. Since the aqueous solution of the adsorbate $\mathrm{Hg}\left(\mathrm{NO}_{3}\right)_{2}$ is acidic, the electron-donating nitrogen and sulfur atoms are readily bound to $\mathrm{H}^{+}$ions to form $\mathrm{N}-\mathrm{H}$ and $\mathrm{S}-\mathrm{H}$ bonds. After all, the formation of $\mathrm{N}-\mathrm{Hg}$ and $\mathrm{S}-\mathrm{Hg}$ coordination bonds suggests that nitrogen and sulfur atoms are the active sites of mercury ion adsorption. 
Based on the XPS analysis, it is reasonable to infer that carbon atoms did not contribute to the chemical adsorption of metal ions. The adsorption mechanism could be that electron-rich $-\mathrm{S}-,-\mathrm{SH}$, and $=\mathrm{N}$ - functional groups in PBT nanosheets coordinated with $\mathrm{Hg}^{2+}$ ions to form a stable complex (Scheme 1), leading to excellent adsorbability.

\section{Comparison of $\mathrm{Hg}^{2+}$ Adsorbability with Other Adsorbents}

On the basis of a careful comparison of the $\mathrm{Hg}^{2+}$ adsorbability onto several typical adsorbents summarized in Table 5 [62-65,68-75], the PBT nanosheets have an even stronger adsorbability toward $\mathrm{Hg}^{2+}$ solutions than the other reported adsorbents, to the best of our knowledge. The adsorption ratio of magnetic functional metal-organic $\mathrm{Fe}_{3} \mathrm{O}_{4} @ \mathrm{Zn}(\mathrm{btb})$ nanospheres [68] and cross-linked magnetic chitosan-phenylthiourea (CSTU) [69] at the dosage of $1.0 \mathrm{~g} \mathrm{~L}^{-1}$ toward $200 \mathrm{mg} \mathrm{L}^{-1} \mathrm{Hg}^{2+}$ is only $64.93 \%$ and $67.50 \%$, respectively. However, the PBT nanosheets at the same dosage achieved an $84.12 \%$ adsorption ratio. At the same time, PBT is an efficient adsorbent having a high adsorption capacity. when the initial concentration of mercury ions was increased to $2000 \mathrm{mg} \mathrm{L}^{-1}$, the adsorption capacity of PBT significantly rose up to $680.01 \mathrm{mg} \mathrm{g}^{-1}$, which is about two times that of polystyrene-triethylenetetramine resin (PS-TETA) [64]. The fact that the PBT nanosheets have powerful adsorbability toward a concentrated $\mathrm{Hg}^{2+}$ solution of $200-2000 \mathrm{mg} \mathrm{L}^{-1}$ hints that the PBT nanosheets will demonstrate very strong treating capability and wonderful durability if treating diluted $\mathrm{Hg}^{2+}$ solutions. Besides, the PBT nanosheets can accomplish equilibrium adsorption toward $200 \mathrm{mg} \mathrm{L}^{-1} \mathrm{Hg}^{2+}$ solution in $1.0 \mathrm{~h}$ at a very fast initial adsorption rate of $10,653 \mathrm{mg} \mathrm{g}^{-1} \mathrm{~h}^{-1}$, but most of the other sorbents could reach equilibrium adsorption in 1.5-24 $\mathrm{h}$ at a much slower initial adsorption rate. Therefore, satisfactory $\mathrm{Hg}^{2+}$ adsorbability should be ascribed to an optimal synergic combination of the three kinds of active groups with moderate specific area of the PBT nanosheets. 
Table 5. Comparison of specific surface area $\left(\mathrm{S}_{\mathrm{BET}}\right)$, average pore diameter, equilibrium adsorption capacity $\left(Q_{\mathrm{e}}\right)$ and adsorption ratio $(q)$, and initial adsorption rate $\left(h_{0}\right)$ of various adsorbents towards $\mathrm{Hg}^{2+}$

\begin{tabular}{|c|c|c|c|c|c|c|c|c|}
\hline Adsorbents & $\mathrm{S}_{\mathrm{BET}}\left(\mathrm{m}^{2} \mathrm{~g}^{-1}\right)$ & $\begin{array}{l}\text { Pore Diameter } \\
(\mathrm{nm})\end{array}$ & {$\left[\mathrm{Hg}^{2+}\right]_{0}\left(\mathrm{mg} \mathrm{L}^{-1}\right)$} & $\begin{array}{l}\text { Adsorbent Dose } \\
\left(\mathrm{g} \mathrm{L}^{-1}\right)\end{array}$ & pH & $Q_{\mathrm{e}}\left(\mathrm{mg} \mathrm{g}^{-1}\right)$ & $q(\%)$ & $h_{0}\left(\mathrm{mg} \mathrm{g}^{-1} \mathrm{~h}^{-1}\right) / t_{\mathrm{Qe}}(\mathrm{h})$ \\
\hline PBT (this work) & 15.85 & 19.4 & $200(2000)$ & 1.0 & 4.68 & $168.23(680.01)$ & $84.12(34)$ & $10,653 / 1.0$ \\
\hline Melamine-based porous polymer networks [62] & 153 & 14.3 & 401.18 & 1.77 & - & 198 & 87.50 & $1.41 / 24$ \\
\hline $\mathrm{Fe}_{3} \mathrm{O}_{4} @ \mathrm{Zn}(\mathrm{btb})$ nanospheres [68] & - & - & 200 & 1.0 & 8 & 129.87 & 64.93 & $0.059 / 0.5$ \\
\hline Cross-linked magnetic chitosan-phenylthiourea (CSTU) [69] & 64.5 & 860 & 200 & 1.0 & 5 & 135 & 67.50 & $139.8 / 3$ \\
\hline Dithiocarbamate chelating resin (DTMAN) [70] & 46.82 & 4.09 & 1003 & 1.0 & 5 & 461.35 & 46.00 & $-/ 0.33$ \\
\hline Hierarchical micro-nano porous carbon material (MNC) [71] & 1978 & 540 & 600 & 1.0 & 6 & 241.2 & 40.20 & $-/ 1.66$ \\
\hline Polyvinyl alcohol (PVA) [72] & - & 12 & 30 & 1.0 & 7 & 25.5 & 85.00 & $-/ 2$ \\
\hline Poly(1-amino-5-chloroanthraquinone) (PACA) [63] & 35 & - & 100.3 & 1.0 & 6 & 83.25 & 83.00 & $-/ 2$ \\
\hline Polystyrene-triethylenetetramine resin (PS-TETA) [64] & - & - & 2000 & 1.0 & 6 & 344.8 & 17.24 & $-/ 14$ \\
\hline $\begin{array}{l}\text { Ethylenediamine-modified magnetic crosslinking chitosan } \\
\text { microspheres (EMCR) [73] }\end{array}$ & 68.6 & 826 & 1003 & 1.0 & 3 & 539.58 & 53.80 & $-/ 2$ \\
\hline $\begin{array}{l}\text { Wool-grafted-poly(cyano-acetic acid } \alpha \text {-amino- } \\
\text { acrylichydrazide) (wool-g-PCAH) chelating fibers [74] }\end{array}$ & - & - & 100 & 0.60 & 5 & 154.32 & 93.3 & $-/ 1.5$ \\
\hline $\begin{array}{l}\text { Impregnated resin containing } \\
\text { 1-(2-thiazolylazo)-2-naphthol (TAN) [75] }\end{array}$ & 750 & 10 & 1000 & 1.0 & 5.5 & 450.45 & 45.04 & $-/ 0.92$ \\
\hline $\begin{array}{l}\text { Modified poly(ethylene terephthalate) chelating fibers } \\
\text { (PET-TSC) [65] }\end{array}$ & 5.785 & - & 150 & 1.0 & 5 & 120.02 & 80.01 & $-/ 0.83$ \\
\hline
\end{tabular}




\section{Conclusions}

Unique poly(2,5-dimercapto-1,3,4-thiadiazole) (PBT) nanosheets have been successfully synthesized through a simple chemical oxidative polymerization under environmentally friendly conditions. The as-synthesized PBT polymers possess several unique characteristics: facile one-pot synthesis; green synthesis conditions (oxidant, $\mathrm{I}_{2}$ or $\mathrm{H}_{2} \mathrm{O}_{2}$; medium, ethanol); high total molar content of sulfur and nitrogen (above 56\%); high polymerization yield (up to $98.47 \%$ ); and high chemoresistance (thermal and chemical stability). The polymerization media, oxidant species, monomer concentrations, oxidant/monomer molar ratios, and polymerization temperature were thoroughly optimized for the formation of uniform PBT nanosheets with a high polymerization yield, tunable size, good chemical resistance except for ammonia, high thermostability, and interesting blue-light emitting fluorescence, as well as high heavy metal ion adsorbability. The UV-Vis, FT-IR, and MALDI/TOF mass spectra, together with the solubility experiment, showed that high molecular weight PBTs were created via S-S linkage at the $S(2)$ and $S(5)$ positions of the monomers. The SEM and TEM analyses show that the as-prepared PBT polymers were nanosheets with a thickness of 89 367 nm. The nanoscale and sulfur/nitrogen-rich features endow this kind of polymer with wonderful performance. Most importantly, PBT nanosheets can be excellent adsorbents for mercury ions, with an adsorption capacity as high as $680.01 \mathrm{mg} \mathrm{g}^{-1}$ and a very rapid initial adsorption rate of up to $10,653 \mathrm{mg} \mathrm{g}^{-1} \mathrm{~h}^{-1}$, which makes them very competitive with most good $\mathrm{Hg}^{2+}$-sorbents previously reported. With these impressive functionalities, PBT nanosheets are seen as promising for many target applications, such as in water treatment, sensors, and electrodes.

Supplementary Materials: The following are available online at www.mdpi.com/2073-4360/10/1/24/s1, Table S1: Solubility and solution color of BT monomer and PBT polymers, Table S2: Main composition and proportion of frontier orbitals in BT, Table S3: Main atomic electron spin densities for BT, Table S4: FT-IR spectra data of solid BT and PBT and their assignments, Table S5: WAXD data of solid BT and PBTs, Table S6: Proposed composition and corresponding theoretical mass-to-charge ratio of PBT molecules, Figure S1: UV-Vis spectra of BT monomer and PBT polymers, Figure S2: Molecular model of BT monomer with minimized energy, Figure S3: Fluorescent emission spectra of PBT solutions in NMP at different concentrations, Figure S4: Nitrogen adsorption-desorption isotherms and pore size distribution curves of fine PBT powders.

Acknowledgments: This work was supported by the National Natural Science Foundation of China (No. 51363012 and 11764026), and the Analysis and Testing Foundation of Kunming University of Science and Technology (No. 2016T20110164).

Author Contributions: Shaojun Huang and Chao Li conceived and designed the experiments; Chao Li and Shaojun Huang performed the experiments; Chungang Min, Yi Xia, Chaofen Yang, and Qiuling Huang analyzed the data; Ping Du and Qiuling Huang contributed reagents/materials/analysis tools; Chao Li and Shaojun Huang wrote the paper.

Conflicts of Interest: The authors declare no conflict of interest.

\section{References}

1. Ran, F.; Yang, Y.L.; Zhao, L.; Niu, X.Q.; Zhang, D.J.; Kong, L.B.; Luo, Y.C.; Kang, L. Preparation of nano-PANI@ $\mathrm{MnO}_{2}$ by surface initiated polymerization method using as a nano-tubular electrode material: The amount effect of aniline on the microstructure and electrochemical performance. J. Energy Chem. 2015, 24, 388-393. [CrossRef]

2. Zalas, M.; Gierczyk, B.; Ceglowski, M.; Schroeder, G. Synthesis of new dendritic antenna-like polypyridine ligands. Chem. Pap. 2012, 66, 733-740. [CrossRef]

3. Gan, L.H.; Xia, X.; Chan, C.Y.; Hu, X.; Zhao, X. Sythesis, characterization and properties of azobenzene side-chain polythiophene. Polym. Adv. Technol. 2003, 14, 260-265. [CrossRef]

4. Kalimuthu, P.; John, S.A. Modification of electrodes with nanostructured functionalized thiadiazole polymer film and its application to the determination of ascorbic acid. Electrochim. Acta 2009, 55, 183-189. [CrossRef]

5. Lu, Q.F.; Huang, M.R.; Li, X.G. Synthesis and heavy-metal-ion sorption of pure sulfophenylenediamine copolymer nanoparticles with intrinsic conductivity and stability. Chem. Eur. J. 2007, 13, 6009-6018. [CrossRef] [PubMed] 
6. Li, X.G.; Lu, Q.F.; Huang, M.R. Self-stabilized nanoparticles of intrinsically conducting copolymers from 5-sulfonic-2-anisidine. Small 2008, 4, 1201-1209. [CrossRef] [PubMed]

7. Qin, T.T.; Li, J.; Luo, H.Q.; Li, M.; Li, N.B. Corrosion inhibition of copper by 2,5-dimercapto-1,3,4-thiadiazole monolayer in acidic solution. Corros. Sci. 2011, 53, 1072-1078. [CrossRef]

8. Pope, J.M.; Sato, T.; Shoji, E.; Oyama, N.; White, K.C.; Buttry, D.A. Organosulfur/conducting polymer composite cathodes II. Spectroscopic determination of the protonation and oxidation states of 2,5-dimercapto-1,3,4-thiadiazole. J. Electrochem. Soc. 2002, 149, A939-A952. [CrossRef]

9. Li, P.; Poon, Y.F.; Li, W.F.; Zhu, H.Y.; Yeap, S.H.; Cao, Y.; Qi, X.B.; Zhou, C.C.; Lamrani, M.; Beuerman, R.W.; et al. A polycationic antimicrobial and biocompatible hydrogel with microbe membrane suctioning ability. Nat. Mater. 2011, 10, 149-156. [CrossRef] [PubMed]

10. Popiolek, L.; Kosikowska, U.; Dobosz, M.; Malm, A. Synthesis and antimicrobial properties of new thiosemicarbazide, 1,2,4-triazole, and 1,3,4-thiadiazole derivatives of sulfanylacetic acid. Phosphorus Sulfur Silicon Relat. Elem. 2012, 187, 468-481. [CrossRef]

11. Jakhar, A.; Makrandi, J.K. Synthesis and antibacterial properties of some novel 2-substituted-6-(4-methyl-6substitutedcinnoline-3-yl)imidazo[2,1-b][1,3,4]thiadiazoles. Indian J. Chem. Sect. B 2010, 49, 1547-1551. [CrossRef]

12. Hamama, W.S.; Ibrahim, M.E.; Raoof, H.A.; Zoorob, H.H. Chemistry of bicyclic $[1,3,4]$ thiadiazole $5-5$ systems containing ring-junction nitrogen. Res. Chem. Intermed. 2017, 43, 6259-6291. [CrossRef]

13. Tzvetkova, P.; Vassileva, P.; Nickolov, R. Modified silica gel with 5-amino-1,3,4-thiadiazole-2- thiol for heavy metal ions removal. J. Porous Mater. 2010, 17, 459-463. [CrossRef]

14. Dias, N.L.; Caetano, L.; do Carmo, D.R.; Rosa, A.H. Preparation of a silica gel modified with 2-amino-1,3,4-thiadiazole for adsorption of metal ions and electroanalytical application. J. Braz. Chem. Soc. 2006, 17, 473-481. [CrossRef]

15. Jing, X.S.; Liu, F.Q.; Yang, X.; Ling, P.P.; Li, L.J.; Long, C.; Li, A.M. Adsorption performances and mechanisms of the newly synthesized $N, N^{\prime}$-di (carboxymethyl) dithiocarbamate chelating resin toward divalent heavy metal ions from aqueous media. J. Hazard. Mater. 2009, 167, 589-596. [CrossRef] [PubMed]

16. El-Shekeil, A.G.; Al-Maydama, H.M.; Al-Shuja'a, O.M. The synthesis, characterization, and DC electrical conductivity of poly[di(2,5-dimercapto-1,3,4-thiadiazole)-metal] complexes. J. Appl. Polym. Sci. 2007, 106, 2427-2435. [CrossRef]

17. Tiwari, M.; Gupta, S.; Prakash, R. One pot synthesis of coordination polymer 2,5-dimercapto-1,3,4thiadiazole-gold and its application in voltammetric sensing of resorcinol. RSC Adv. 2014, 4, 25675-25682. [CrossRef]

18. Shouji, E.; Buttry, D.A. An investigation of the effect of pyridine derivatives on the oxidative polymerization process of 2,5-dimercapto-1,3,4-thiadiazole and its disulfide dimer. J. Phys. Chem. B 1998, 102, 1444-1449. [CrossRef]

19. Varghese, A.; Chitravathi, S.; Munichandraiah, N. Electrocatalytic oxidation and determination of morin at a poly(2,5-dimercapto-1,3,4-thiadiazole) modified carbon fiber paper electrode. J. Electrochem. Soc. 2016, 163, B471-B477. [CrossRef]

20. Sun, J.S.; Zhang, R.F.; Wang, D.Q. catena-Poly[[trimethyltin(IV)]- $\mu$-[5-(2-thienyl-methyleneamino)-1,3,4thiadiazole-2-thiolato- $\left.\kappa^{2} N^{4}: S^{2}\right]$ ]. Acta Crystallogr. Sect. E 2007, 63, m418-m419. [CrossRef]

21. Qin, J.H.; Wang, J.G.; Hu, P.Z. catena-Poly[[[bis[2,2'-(propane-1,3-diyl-dithio) bis(1,3,4-thiadiazole)- $\left.\kappa N^{4}\right]$ copper(II)]-bis[ $\mu$-2,2'-(propane-1,3-diyl-dithio)bis(1,3,4-thiadiazole)- $\left.\left.\kappa^{2} N^{4}: N^{4 \prime}\right]\right]$ bis(perchlorate)]. Acta Crystallogr. Sect. E 2009, 65, m349-m350. [CrossRef] [PubMed]

22. Qin, J.H.; Wang, J.G.; Hu, P.Z. Crystal structure of ethanolatopenta $\left\{2,2^{\prime}\right.$-[1,2-propanedithio-bis(1,3,4-thiadiazole)]\} dicopper(II) tetrakisperchlorate, $\left[\mathrm{Cu}_{2}\left(\mathrm{C}_{2} \mathrm{H}_{5} \mathrm{OH}\right)\left(\mathrm{C}_{7} \mathrm{H}_{8} \mathrm{~N}_{4} \mathrm{~S}_{4}\right)_{5}\right]\left[\mathrm{ClO}_{4}\right]_{4}$. Z. Kristallogr. NCS 2010, 225, 339-342.

23. Maadadi, R.; Pevzner, L.M.; Petrov, M.L. Thiadiazole ring opening in the derivatives of 2-substituted 5-(1,2,3-thiadiazol-4-yl)-3-furoic acid under the action of bases. Russ. J. Gen. Chem. 2017, 87, 259-265. [CrossRef]

24. Soylak, M.; Unsal, Y.E.; Yilmaz, E.; Tuzen, M. Determination of rhodamine B in soft drink, waste water and lipstick samples after solid phase extraction. Food Chem. Toxicol. 2011, 49, 1796-1799. [CrossRef] [PubMed]

25. Duran, A.; Tuzen, M.; Soylak, M. Trace element concentrations of some pet foods commercially available in Turkey. Food Chem. Toxicol. 2010, 48, 2833-2837. [CrossRef] [PubMed]

26. Branescu, S.V.; Popescu, A. Survey of the concentration of some heavy metals in waste waters from Ramnicu Valcea Chemical Plant at the Biological Purification Plant. Rev. Chim. 2008, 59, 902-905. 
27. Zheng, F.; Hu, B. MPTS-silica coated capillary microextraction on line hyphenated with inductively coupled plasma atomic emission spectrometry for the determination of $\mathrm{Cu}, \mathrm{Hg}$ and $\mathrm{Pb}$ in biological samples. Talanta 2007, 73, 372-379. [CrossRef] [PubMed]

28. Yusoh, R.; Horprathum, M.; Eiamchai, P.; Chanyawadee, S.; Aiempanakit, K. Determination of the thickness and optical constants of $\mathrm{ZrO}_{2}$ by spectroscopic ellipsometry and spectrophotometric method. Procedia Eng. 2011, 8, 223-227. [CrossRef]

29. Zhang, L.; Chang, X.; Hu, Z.; Zhang, L.J.; Shi, J.P.; Gao, R. Selective solid phase extraction and preconcentration of mercury(II) from environmental and biological samples using nanometer silica functionalized by 2,6-pyridine dicarboxylic acid. Microchim. Acta 2010, 168, 79-85. [CrossRef]

30. Li, X.G.; Li, H.; Huang, M.R.; Moloney, M.G. Synthesis and multifunctionality of self-stabilized poly(aminoanthraquinone) nanofibrils. J. Phys. Chem. C 2011, 115, 9486-9497. [CrossRef]

31. Li, X.G.; Li, J.; Meng, Q.K.; Huang, M.R. Interfacial synthesis and widely controllable conductivity of polythiophene microparticles. J. Phys. Chem. B 2009, 113, 9718-9727. [CrossRef] [PubMed]

32. Huang, S.J.; Min, C.G.; Liao, Y.Z.; Du, P.; Sun, H.; Zhu, Y.Q.; Ren, A.M. Intrinsically conducting polyaminoanthraquinone nanofibrils: Interfacial synthesis, formation mechanism and lead adsorbents. RSC Adv. 2014, 4, 47657-47669. [CrossRef]

33. Huang, M.R.; Huang, S.J.; Li, X.G. Facile Synthesis of polysulfoaminoanthraquinone nanosorbents for rapid removal and ultrasensitive fluorescent detection of heavy metal ions. J. Phys. Chem. C 2011, 115, 5301-5315. [CrossRef]

34. Wang, D.; Li, S.; Ying, Y.; Wang, M.J.; Xiao, H.M.; Chen, Z.X. Theoretical and experimental studies of structure and inhibition efficiency of imidazoline derivatives. Corros. Sci. 1999, 41, 1911-1919. [CrossRef]

35. Shouji, E.; Oyama, N. Examination of the cleavage and formation of the disulfide bond in poly[dithio2,5-(1,3,4-thiadiazole)] by redox reaction. J. Electroanal. Chem. 1996, 410, 229-234. [CrossRef]

36. Zhao, Y.X.; Sun, X.Y. Spectrometric Identification of Organic Molecular Structures, 1st ed.; Science Press: Beijing, China, 2003; pp. 373-388. ISBN 7-03-010866-3.

37. Aydogdu, G.; Gunendi, G.; Zeybek, D.K.; Zeybek, B.; Pekyardimci, S. A novel electrochemical DNA biosensor based on poly-(5-amino-2-mercapto-1,3,4-thiadiazole) modified glassy carbon electrode for the determination of nitrofurantoin. Sens. Actuators B Chem. 2014, 197, 211-219. [CrossRef]

38. Revin, S.B.; John, S.A. Electropolymerization of 3-amino-5-mercapto-1,2,4-triazole on glassy carbon electrode and its electrocatalytic activity towards uric acid. Electrochim. Acta 2011, 56, 8934-8940. [CrossRef]

39. Xue, Y.; Sheng, Z.H.; Zhao, H.; Wu, Z.J.; Li, X.J.; He, Y.J.; Yuan, Z.B. Electrochemical synthesis and characterization of a novel thiazole-based copolymer and its application in biosensor. Electrochim. Acta 2012, 59, 256-263. [CrossRef]

40. Wang, X.; Wang, L.; Zou, H.; Qian, W.; Liao, Y.Z. Simple synthesis of conducting poly (2-aminothiazole) with high molecular weight. Colloid Polym. Sci. 2015, 293, 2027-2034. [CrossRef]

41. Wei, Y.; Focke, W.W.; Wnek, G.E.; Ray, A.; MacDiarmid, A.G. Synthesis and electrochemistry of alkyl ring-substituted polyanilines. J. Phys. Chem. 1989, 93, 495-499. [CrossRef]

42. Gao, J.; Lowe, M.A.; Conte, S.; Burkhardt, S.E.; Abruna, H.D. Poly (2,5-dimercapto-1,3,4-thiadiazole) as a cathode for rechargeable lithium batteries with dramatically improved performance. Chem. Eur. J. 2012, 18, 8521-8526. [CrossRef] [PubMed]

43. Vieira, R.S.; Oliveira, M.L.M.; Guibal, E.; Rodriguez-Castellon, E.; Beppu, M.M. Copper, mercury and chromium adsorption on natural and crosslinked chitosan films: An XPS investigation of mechanism. Colloids Surf. A 2011, 374, 108-114. [CrossRef]

44. Kalimuthu, P.; John, S.A. Nanostructured electropolymerized film of 5-amino-2-mercapto-1,3,4-thiadiazole on glassy carbon electrode for the selective determination of L-cysteine. Electrochem. Commun. 2009, 11, 367-370. [CrossRef]

45. Zhou, Y.T.; Branford-White, C.; Nie, H.L.; Zhu, L.M. Adsorption mechanism of $\mathrm{Cu}^{2+}$ from aqueous solution by chitosan-coated magnetic nanoparticles modified with alpha-ketoglutaric acid. Colloids Surf. B 2009, 74, 244-252. [CrossRef] [PubMed]

46. Zhang, X.; Bai, R.B. Mechanisms and kinetics of humic acid adsorption onto chitosan-coated granules. J. Colloid Interface Sci. 2003, 264, 30-38. [CrossRef] 
47. Ando, S.; Ueda, M. Density functional theory calculations of the local spin densities of 3-substituted thiophenes and the oligomerization mechanism of 3-methylsulfanyl thiophene. Synth. Met. 2002, 129, 207-213. [CrossRef]

48. Doskocz, J.; Doskocz, M.; Roszak, S.; Soloducho, J.; Leszcynski, J. Theoretical studies of symmetric five-membered heterocycle derivatives of carbazole and fluorene: Precursors of conducting polymers. J. Phys. Chem. A 2006, 110, 13989-13994. [CrossRef] [PubMed]

49. Yin, F.X.; Wang, D.R.; Zhang, Z.; Zhang, C.W.; Zhang, Y.G. Synthesis of mesoporous hollow polypyrrole spheres and the utilization as supports of high loading of Pt nanoparticles. Mater. Lett. 2017, 207, 225-229. [CrossRef]

50. Kitao, T.; MacLean, M.W.A.; Le Ouay, B.; Sasaki, Y.; Tsujimoto, M.; Kitagawa, S.; Uemura, T. Preparation of polythiophene microrods with ordered chain alignment using nanoporous coordination template. Polym. Chem. 2017, 8, 5077-5081. [CrossRef]

51. Huang, J.; Kaner, R.B. Nanofiber formation in the chemical polymerization of aniline: A mechanistic study. Angew. Chem. Int. Ed. 2004, 43, 5817-5821. [CrossRef] [PubMed]

52. Chiou, N.R.; Epstein, A.J. Polyaniline nanofibers prepared by dilute polymerization. Adv. Mater. 2010, 17, 1679-1683. [CrossRef]

53. Zhang, Y.M.; Dou, C.F.; Wang, W.P.; Wang, Q.; Feng, N.C. Synthesis of uniform polyaniline nanosheets and nanotubes: Dependence of morphology on the pH. Macromol. Res. 2016, 24, 663-669. [CrossRef]

54. Liao, Y.Z.; Strong, V.; Wang, Y.; Li, X.G.; Wang, X.; Kaner, R.B. Oligotriphenylene nanofiber sensors for detection of nitro-based explosives. Adv. Funct. Mater. 2012, 22, 726-735. [CrossRef]

55. Li, X.G.; Li, H.; Huang, M.R. Productive synthesis and properties of polydiaminoanthraquinone and its pure self-stabilized nanoparticles with widely adjustable electroconductivity. Chem. Eur. J. 2007, 13, 8884-8896. [CrossRef] [PubMed]

56. Schwarze, T.; Dosche, C.; Flehr, R.; Klamroth, T.; Lohmannsroben, H.G.; Saalfrank, P.; Cleve, E.; Buschmanne, H.J.; Holdt, H.J. Combination of a CT modulated PET and an intramolecular excimer formation to quantify $\mathrm{PdCl}_{2}$ by large fluorescence enhancement. Chem. Commun. 2010, 46, 2034-2036. [CrossRef] [PubMed]

57. Ramachandram, B.; Samanta, A. Transition metal ion induced fluorescence enhancement of 4-(N,N-dimethylethylenediamino)-7-nitrobenz-2-oxa-1,3-diazole. J. Phys. Chem. A 1998, 102, 10579-10587. [CrossRef]

58. Tang, L.J.; Zhao, G.Y.; Jin, Z. Fluorescent “off-on" recognition of copper(II) ions by a simple carbazole-based probe. Chem. Res. Appl. 2013, 25, 946-951.

59. Ci, Y.X.; Zhou, T.Z. Application of soft and hard acids and bases principle to analytical chemistry. Chin. J. Anal. Chem. 1982, 10, 441-446.

60. Pearson, R.G. Hard and soft acids and bases. J. Am. Chem. Soc. 1963, 85, 3533-3539. [CrossRef]

61. Naiya, T.K.; Bhattacharya, A.K.; Mandal, S.; Das, S.K. The sorption of lead(II) ions on rice husk ash. J. Hazard. Mater. 2009, 163, 1254-1264. [CrossRef] [PubMed]

62. Yang, G.W.; Han, H.Y.; Du, C.Y.; Luo, Z.H.; Wang, Y.J. Facile synthesis of melamine-based porous polymer networks and their application for removal of aqueous mercury ions. Polymer 2010, 51, 6193-6202. [CrossRef]

63. Huang, S.J.; Ma, C.Z.; Liao, Y.Z.; Min, C.G.; Du, P.; Jiang, Y.B. Removal of mercury(II) from aqueous solutions by adsorption on poly(1-amino-5-chloroanthraquinone) nanofibrils: Equilibrium, kinetics, and mechanism studies. J. Nanomater. 2016, 2016, 7245829. [CrossRef]

64. Xiong, C.H.; Yao, C.P. Synthesis, characterization and application of triethylenetetramine modified polystyrene resin in removal of mercury, cadmium and lead from aqueous solutions. Chem. Eng. J. 2009, 155, 844-850. [CrossRef]

65. Monier, M.; Abdel-Latif, D.A. Modification and characterization of PET fibers for fast removal of $\mathrm{Hg}(\mathrm{II})$, $\mathrm{Cu}(\mathrm{II})$ and $\mathrm{Co}(\mathrm{II})$ metal ions from aqueous solutions. J. Hazard. Mater. 2013, 250, 122-130. [CrossRef] [PubMed]

66. Ho, Y.S. Removal of copper ions from aqueous solution by tree fern. Water Res. 2003, 37, 2323-2330. [CrossRef]

67. Yu, X.Y.; Luo, T.; Zhang, Y.X.; Jia, Y.; Zhu, B.J.; Fu, X.C.; Liu, J.H.; Huang, X.J. Adsorption of Lead(II) on $\mathrm{O}_{2}$-plasma-oxidized multiwalled carbon nanotubes: Thermodynamics, kinetics, and desorption. ACS Appl. Mater. Interface 2011, 3, 2585-2593. [CrossRef] [PubMed]

68. Nouri, R.; Tahmasebi, E.; Morsali, A. Capability of magnetic functional metal-organic nanocapsules for removal of mercury(II) ions. Mater. Chem. Phys. 2017, 198, 310-316. [CrossRef] 
69. Monier, M.; Abdel-Latif, D.A. Preparation of cross-linked magnetic chitosan-phenylthiourea resin for adsorption of $\mathrm{Hg}(\mathrm{II}), \mathrm{Cd}(\mathrm{II})$ and $\mathrm{Zn}(\mathrm{II})$ ions from aqueous solutions. J. Hazard. Mater. 2012, 209, $240-249$. [CrossRef] [PubMed]

70. Shaaban, A.F.; Fadel, D.A.; Mahmoud, A.A.; Elkomy, M.A.; Elbahy, S.M. Synthesis and characterization of dithiocarbamate chelating resin and its adsorption performance toward $\mathrm{Hg}(\mathrm{II}), \mathrm{Cd}(\mathrm{II})$ and $\mathrm{Pb}$ (II) by batch and fixed-bed column methods. J. Environ. Chem. Eng. 2013, 1, 208-217. [CrossRef]

71. Liu, C.B.; Chen, Z.G.; Ni, C.Y.; Chen, F.; Gu, C.; Cao, Y.; Wu, Z.Y.; Li, P. Adsorption of phenol from aqueous solution by a hierarchical micro-nano porous carbon material. Rare Met. 2012, 31, 582-589. [CrossRef]

72. Jana, S.; Purkait, M.K.; Mohanty, K. Polymer enhanced ultrafiltration of mercury using chitosan impregnated ceramic membrane. Desalin. Water Treat. 2012, 37, 321-330. [CrossRef]

73. Zhou, L.M.; Liu, Z.R.; Liu, J.H.; Huang, Q.W. Adsorption of $\mathrm{Hg}(\mathrm{II})$ from aqueous solution by ethylenediamine-modified magnetic crosslinking chitosan microspheres. Desalination 2010, 258, 41-47. [CrossRef]

74. Monier, M.; Nawar, N.; Abdel-Latif, D.A. Preparation and characterization of chelating fibers based on natural wool for removal of $\mathrm{Hg}(\mathrm{II}), \mathrm{Cu}(\mathrm{II})$ and $\mathrm{Co}(\mathrm{II})$ metal ions from aqueous solutions. J. Hazard. Mater. 2010, 184, 118-125. [CrossRef] [PubMed]

75. Hosseini-Bandegharaei, A.; Hosseini, M.S.; Jalalabadi, Y.; Sarwghadi, M.; Nedaie, M.; Taherian, A.; Ghaznavi, A.; Eftekhari, A. Removal of $\mathrm{Hg}$ (II) from aqueous solutions using a novel impregnated resin containing 1-(2-thiazolylazo)-2-naphthol (TAN). Chem. Eng. J. 2011, 168, 1163-1173. [CrossRef]

(C) 2017 by the authors. Licensee MDPI, Basel, Switzerland. This article is an open access article distributed under the terms and conditions of the Creative Commons Attribution (CC BY) license (http://creativecommons.org/licenses/by/4.0/). 